\title{
The shrinking projection method for solving generalized equilibrium problems and common fixed points for asymptotically quasi- $\varphi$-nonexpansive mappings
}

Siwaporn Saewan and Poom Kumam*

\footnotetext{
* Correspondence: poom. kum@kmutt.ac.th

Department of Mathematics, Faculty of Science, King Mongkut's University of Technology Thonburi (KMUTT), Bangmod, Bangkok

10140, Thailand
}

\begin{abstract}
In this article, we introduce a new hybrid projection iterative scheme based on the shrinking projection method for finding a common element of the set of solutions of the generalized mixed equilibrium problems and the set of common fixed points for a pair of asymptotically quasi- $\varphi$-nonexpansive mappings in Banach spaces and set of variational inequalities for an $\alpha$-inverse strongly monotone mapping. The results obtained in this article improve and extend the recent ones announced by Matsushita and Takahashi (Fixed Point Theory Appl. 2004(1):37-47, 2004), Qin et al. (Appl. Math. Comput. 215:3874-3883, 2010), Chang et al. (Nonlinear Anal. 73:22602270, 2010), Kamraksa and Wangkeeree (J. Nonlinear Anal. Optim.: Theory Appl. 1 (1):55-69, 2010) and many others.
\end{abstract}

AMS Subject Classification: 47H05, 47H09, 47J25, 65J15.

Keywords: Generalized mixed equilibrium problem, Asymptotically quasi- $\varphi$ ?叉?-nonexpansive mapping, Strong convergence theorem, Variational inequality, Banach spaces

\section{Introduction}

Let $E$ be a Banach space with norm $\|\cdot\|, C$ be a nonempty closed convex subset of $E$, and let $E^{*}$ denote the dual of $E$. Let $f: C \times C \rightarrow \mathbb{R}$ be a bifunction, $\phi: C \rightarrow \mathbb{R}$ be a real-valued function, and $B: C \rightarrow E^{*}$ be a mapping. The generalized mixed equilibrium problem, is to find $x \in C$ such that

$$
f(x, y)+\langle B x, y-x\rangle+\varphi(y)-\varphi(x) \geq 0, \quad \forall y \in C .
$$

The set of solutions to (1.1) is denoted by $\operatorname{GMEP}(f, B, \phi)$, i.e.,

$$
\operatorname{GMEP}(f, B, \varphi)=\{x \in C: f(x, y)+\langle B x, y-x\rangle+\varphi(y)-\varphi(x) \geq 0, \quad \forall y \in C\} .
$$

If $B \equiv 0$, then the problem (1.1) reduces into the mixed equilibrium problem for $f$, denoted by $\operatorname{MEP}(f, \phi)$, is to find $x \in C$ such that

$$
f(x, y)+\varphi(y)-\varphi(x) \geq 0, \quad \forall y \in C .
$$

If $\phi \equiv 0$, then the problem (1.1) reduces into the generalized equilibrium problem, denoted by $\operatorname{GEP}(f, B)$, is to find $x \in C$ such that

(c) 2011 Saewan and Kumam; licensee Springer. This is an Open Access article distributed under the terms of the Creative Commons Attribution License (http://creativecommons.org/licenses/by/2.0), which permits unrestricted use, distribution, and reproduction in any medium, provided the original work is properly cited. 


$$
f(x, y)+\langle B x, y-x\rangle \geq 0, \quad \forall y \in C .
$$

If $f \equiv 0$, then the problem (1.1) reduces into the mixed variational inequality of Browder type, denoted by $\operatorname{MVI}(B, C)$, is to find $x \in C$ such that

$$
\langle B x, y-x\rangle+\varphi(y)-\varphi(x) \geq 0, \quad \forall y \in C .
$$

If $\phi \equiv 0$, then the problem (1.5) reduces into the classical variational inequality, denoted by $\operatorname{VI}(B, C)$, which is to find $x \in C$ such that

$$
\langle B x, y-x\rangle \geq 0, \quad \forall y \in C .
$$

If $B \equiv 0$ and $\phi \equiv 0$, then the problem (1.1) reduces into the equilibrium problem for $f$, denoted by $\operatorname{EP}(f)$, which is to find $x \in C$ such that

$$
f(x, y) \geq 0, \quad \forall y \in C .
$$

If $f \equiv 0$, then the problem (1.3) reduces into the minimize problem, denoted by Argmin $(\phi)$, which is to find $x \in C$ such that

$$
\varphi(y)-\varphi(x) \geq 0, \quad \forall y \in C .
$$

The above formulation (1.6) was shown in [1] to cover monotone inclusion problems, saddle point problems, variational inequality problems, minimization problems, optimization problems, variational inequality problems, vector equilibrium problems, and Nash equilibria in noncooperative games. In addition, there are several other problems, for example, the complementarity problem, fixed point problem and optimization problem, which can also be written in the form of an $\operatorname{EP}(f)$. In other words, the $\mathrm{EP}(f)$ is an unifying model for several problems arising in physics, engineering, science, optimization, economics, etc. In the last two decades, many articles have appeared in the literature on the existence of solutions of $\operatorname{EP}(f)$; see, for example [1-4] and references therein. Some solution methods have been proposed to solve the $\operatorname{EP}(f)$ in Hilbert spaces and Banach spaces; see, for example [5-20] and references therein.

A Banach space $E$ is said to be strictly convex if $\left\|\frac{x+y}{2}\right\|<1$ for all $x, y \in E$ with $\|x\|$ $=\|y\|=1$ and $x \neq y$. Let $U=\{x \in E:\|x\|=1\}$ be the unit sphere of $E$. Then, a Banach space $E$ is said to be smooth if the limit $\lim _{t \rightarrow 0} \frac{\|x+t y\|-\|x\|}{t}$ exists for each $x, y$ $\in U$. It is also said to be uniformly smooth if the limit exists uniformly in $x, y \in U$. Let $E$ be a Banach space. The modulus of convexity of $E$ is the function $\delta:[0,2] \rightarrow[0,1]$ defined by

$$
\delta(\varepsilon)=\inf \left\{1-\left\|\frac{x+y}{2}\right\|: x, y \in E,\|x\|=\|y\|=1,\|x-y\| \geq \varepsilon\right\} .
$$

A Banach space $E$ is uniformly convex if and only if $\delta(\varepsilon)>0$ for all $\varepsilon \in(0,2]$. Let $p$ be a fixed real number with $p \geq 2$. A Banach space $E$ is said to be $p$-uniformly convex if there exists a constant $c>0$ such that $\delta(\varepsilon) \geq c \varepsilon^{p}$ for all $\varepsilon \in[0,2]$; see [21,22] for more details. Observe that every $p$-uniformly convex is uniformly convex. One should note that no Banach space is $p$-uniformly convex for $1<p<2$. It is well known that a Hilbert space is 2-uniformly convex, uniformly smooth. For each $p>1$, the generalized duality mapping $J_{p}: E \rightarrow 2^{E^{*}}$ is defined by 


$$
J_{p}(x)=\left\{x^{*} \in E^{*}:\left\langle x, x^{*}\right\rangle=\|x\|^{p},\left\|x^{*}\right\|=\|x\|^{p-1}\right\}
$$

for all $x \in E$. In particular, $J=J_{2}$ is called the normalized duality mapping. If $E$ is a Hilbert space, then $J=I$, where $I$ is the identity mapping.

A set valued mapping $U: E \rightrightarrows E^{*}$ with graph $G(U)=\left\{\left(x, x^{*}\right): x^{*} \in U x\right\}$, domain $D(U)$ $=\{x \in \mathrm{E}: U x \neq \varnothing\}$, and $\operatorname{rang} R(U)=\mathrm{U}\{U x: x \in D(U)\}$. $U$ is said to be monotone if $\langle x$ $\left.y, x^{*}-y^{*}\right\rangle \geq 0$ whenever $x^{*} \in U x, y^{*} \in U y$. A monotone operator $U$ is said to be maximal monotone if its graph is not properly contained in the graph of any other monotone operator. We know that if $U$ is maximal monotone, then the solution set $U^{-1} 0=$ $\{x \in D(U): 0 \in U x\}$ is closed and convex. It is knows that $U$ is a maximal monotone if and only if $R(J+r U)=E^{*}$ for all $r>0$ when $E$ is a reflexive, strictly convex and smooth Banach space (see [23]).

Recall that let $A: C \rightarrow E^{*}$ be a mapping. Then, $\mathrm{A}$ is called

(i) monotone if

$$
\langle A x-A y, x-y\rangle \geq 0, \quad \forall x, y \in C,
$$

(ii) $\alpha$-inverse-strongly monotone if there exists a constant $\alpha>0$ such that

$$
\langle A x-A y, x-y\rangle \geq \alpha\|A x-A y\|^{2}, \quad \forall x, y \in C .
$$

The class of inverse-strongly monotone mappings has been studied by many researchers to approximating a common fixed point; see [24-29] for more details.

Recall that a mappings $T: C \rightarrow C$ is said to be nonexpansive if

$$
\|T x-T y\| \leq\|x-y\|, \text { for all } x, y \in C .
$$

$T$ is said to be quasi-nonexpansive if $F(T) \neq \varnothing$, and

$$
\|T x-y\| \leq\|x-y\|, \text { for all } x \in C, y \in F(T) .
$$

$T$ is said to be asymptotically nonexpansive if there exists a sequence $\left\{k_{n}\right\} \subset[1, \infty)$ with $k_{n} \rightarrow 1$ as $n \rightarrow \infty$ such that

$$
\left\|T^{n} x-T^{n} y\right\| \leq k_{n}\|x-y\|, \text { for all } x, y \in C .
$$

$T$ is said to be asymptotically quasi-nonexpansive if $F(T) \neq \varnothing$ and there exists a sequence $\left\{k_{n}\right\} \subset[1, \infty)$ with $k_{n} \rightarrow 1$ as $n \rightarrow \infty$ such that

$$
\left\|T^{n} x-y\right\| \leq k_{n}\|x-y\|, \text { for all } x \in C, y \in F(T) .
$$

$T$ is called uniformly L-Lipschitzian continuous if there exists $L>0$ such that

$$
\left\|T^{n} x-T^{n} y\right\| \leq L\|x-y\|, \text { for all } x, y \in C .
$$

The class of asymptotically nonexpansive mappings was introduced by Goebel and Kirk [30] in 1972. Since 1972, a host of authors have studied the weak and strong convergence of iterative processes for such a class of mappings.

If $C$ is a nonempty closed convex subset of a Hilbert space $H$ and $P_{C}: H \rightarrow C$ is the metric projection of $H$ onto $C$, then $P_{C}$ is a nonexpansive mapping. This fact actually characterizes Hilbert spaces and, consequently, it is not available in more general Banach spaces. In this connection, Alber [31] recently introduced a generalized projection operator $C$ in Banach space $E$ which is an analogue of the metric projection in Hilbert spaces. 
Let $E$ be a smooth, strictly convex and reflexive Banach spaces and $C$ be a nonempty, closed convex subset of $E$. We consider the Lyapunov functional $\varphi: E \times E \rightarrow \mathbb{R}^{+}$ defined by

$$
\phi(y, x)=\|y\|^{2}-2\langle y, J x\rangle+\|x\|^{2}
$$

for all $x, y \in E$, where $J$ is the normalized duality mapping from $E$ to $E^{*}$.

Observe that, in a Hilbert space $H$, (1.9) reduces to $\varphi(y, x)=\|x-y\|^{2}$ for all $x, y \in$ $H$. The generalized projection $\Pi_{C}: E \rightarrow C$ is a mapping that assigns to an arbitrary point $x \in E$ the minimum point of the functional $\varphi(y, x)$; that is, $\Pi_{C} x=x^{*}$, where $x^{*}$ is the solution to the minimization problem:

$$
\phi\left(x^{*}, x\right)=\inf _{y \in C} \phi(y, x) .
$$

The existence and uniqueness of the operator $\Pi_{C}$ follows from the properties of the functional $\varphi(y, x)$ and strict monotonicity of the mapping $J$ (see, for example, [9,32-34]). In Hilbert spaces, $\Pi_{C}=P_{C}$. It is obvious from the definition of the function $\varphi$ that

(1) $(\|y\|-\|x\|)^{2} \leq \varphi(y, x) \leq(\|y\|+\|x\|)^{2}$ for all $x, y \in E$.

(2) $\varphi(x, y)=\varphi(x, z)+\varphi(z, y)+2\langle x-z, J z-J y\rangle$ for all $x, y, z \in E$.

(3) $\varphi(x, y)=\langle x, J x-J y\rangle+\langle y-x, J y\rangle \leq\|x\|\|J x-J y\|+\|y-x\|\|y\|$ for all $x, y \in E$.

(4) If $E$ is a reflexive, strictly convex and smooth Banach space, then, for all $x, y \in$ E,

$$
\phi(x, y)=0 \text { if and only if } x=y .
$$

By the Hahn-Banach theorem, $J(x) \neq \varnothing$ for each $x \in E$, for more details see [35,36].

Remark 1.1. It is also known that if $E$ is uniformly smooth, then $J$ is uniformly norm-to-norm continuous on each bounded subset of $E$. Also, it is well known that if $E$ is a smooth, strictly convex and reflexive Banach space, then the normalized duality mapping $J: E \rightarrow 2^{E^{*}}$ is single-valued, one-to-one and onto (see [35]).

Let $C$ be a closed convex subset of $E$, and let $T$ be a mapping from $C$ into itself. We denote by $F(T)$ the set of fixed point of $T$. A point $p$ in $C$ is said to be an asymptotic fixed point of $T$ [37] if $C$ contains a sequence $\left\{x_{n}\right\}$ which converges weakly to $p$ such that $\lim _{n \rightarrow \infty}|| x_{n}-T x_{n} \|=0$. The set of asymptotic fixed points of $T$ will be denoted by $\hat{F}(T)$.

A point $p$ in $C$ is said to be a strong asymptotic fixed point of $T$ [37] if $C$ contains a sequence $\left\{x_{n}\right\}$ which converges strong to $p$ such that $\lim _{n \rightarrow \infty}|| x_{n}-T x_{n}||=0$. The set of strong asymptotic fixed points of $S$ will be denoted by $\widetilde{F}(T)$.

A mapping $T$ is called relatively nonexpansive [38-40] if $\hat{F}(T)=F(T)$ and

$$
\phi(p, T x) \leq \phi(p, x) \forall x \in C \text { and } p \in F(T) .
$$

The asymptotic behavior of relatively nonexpansive mappings were studied in $[38,39]$.

A mapping $T: C \rightarrow C$ is said to be weak relatively nonexpansive if $\widetilde{F}(T)=F(T)$ and

$$
\phi(p, T x) \leq \phi(p, x) \forall x \in C \text { and } p \in F(T) .
$$


A mapping $T$ is called hemi-relatively nonexpansive if $F(T) \neq \varnothing$ and

$$
\phi(p, T x) \leq \phi(p, x) \forall x \in C \text { and } p \in F(T) .
$$

A mapping $T$ is said to be relatively asymptotically nonexpansive [32,41] if $\hat{F}(T)=F(T) \neq \emptyset$ and there exists a sequence $\left\{k_{n}\right\} \subset[0, \infty)$ with $k_{n} \rightarrow 1$ as $n \rightarrow \infty$ such that

$$
\phi\left(p, T^{n} x\right) \leq k_{n} \phi(p, x) \forall x \in C, p \in F(T) \text { and } n \geq 1 .
$$

Remark 1.2. Obviously, relatively nonexpansive implies weak relatively nonexpansive and both also imply hemi-relatively nonexpansive. Moreover, the class of relatively asymptotically nonexpansive is more general than the class of relatively nonexpansive mappings.

We note that hemi-relatively nonexpansive mappings are sometimes called quasi- $\varphi$ nonexpansive mappings.

We recall the following :

(i) $T: C \rightarrow C$ is said to be $\varphi$-nonexpansive [42,43] if $\varphi(T x, T y) \leq \varphi(x, y)$ for all $x$, $y \in C$.

(ii) $T: C \rightarrow C$ is said to be quasi- $\varphi$-nonexpansive $[42,43]$ if $F(T) \neq \varnothing$ and $\varphi(p, T x)$ $\leq \varphi(p, x)$ for all $x \in C$ and $p \in F(T)$.

(iii) $T: C \rightarrow C$ is said to be asymptotically $\varphi$-nonexpansive [43] if there exists a sequence $\left\{k_{n}\right\} \subset[0, \infty)$ with $k_{n} \rightarrow 1$ as $n \rightarrow \infty$ such that $\varphi\left(T^{n} x, T^{n} y\right) \leq k_{n} \varphi(x, y)$ for all $x, y \in C$.

(iv) $T: C \rightarrow C$ is said to be asymptotically quasi- $\varphi$-nonexpansive [43] if $F(T) \neq \varnothing$ and there exists a sequence $\left\{k_{n}\right\} \subset[0, \infty)$ with $k_{n} \rightarrow 1$ as $n \rightarrow \infty$ such that $\varphi(p$, $\left.T^{n} x\right) \leq k_{n} \varphi(p, x)$ for all $x \in C, p \in F(T)$ and $n \geq 1$.

Remark 1.3. (i) The class of (asymptotically) quasi- $\varphi$-nonexpansive mappings is more general than the class of relatively (asymptotically) nonexpansive mappings, which requires the strong restriction $\hat{F}(T)=F(T)$.

(ii) In real Hilbert spaces, the class of (asymptotically) quasi- $\varphi$-nonexpansive mappings is reduced to the class of (asymptotically) quasi-nonexpansive mappings.

Let $T$ be a nonlinear mapping, $T$ is said to be uniformly asymptotically regular on $C$ if

$$
\lim _{n \rightarrow \infty}\left(\sup _{x \in C}\left\|T^{n+1} x-T^{n} x\right\|\right)=0 .
$$

$T: C \rightarrow C$ is said to be closed if for any sequence $\left\{x_{n}\right\} \subset C$ such that $\lim _{n \rightarrow \infty} x_{n}=x_{0}$ and $\lim _{n \rightarrow \infty} T x_{n}=y_{0}$, then $T x_{0}=y_{0}$.

We give some examples which are closed and asymptotically quasi- $\varphi$-nonexpansive.

Example 1.4. (1). Let $E$ be a uniformly smooth and strictly convex Banach space and $U \subset E \times E^{*}$ be a maximal monotone mapping such that its zero set $U^{-1} 0$ is nonempty. Then, $J_{r}=(J+r U)^{-1} J$ is a closed and asymptotically quasi- $\varphi$-nonexpansive mapping 
from $E$ onto $D(U)$ and $F\left(J_{r}\right)=U^{-1} 0$.

(2). Let $\Pi_{C}$ be the generalized projection from a smooth, strictly convex and reflexive Banach space $E$ onto a nonempty closed and convex subset $C$ of $E$. Then $\Pi_{C}$ is a closed and asymptotically quasi- $\varphi$-nonexpansive mapping from $E$ onto $C$ with $F$ $\left(\Pi_{C}\right)=C$.

Recently, Matsushita and Takahashi [44] obtained the following results in a Banach space.

Theorem MT. Let $E$ be a uniformly convex and uniformly smooth Banach space, let $C$ be a nonempty closed convex subset of $E$, let $T$ be a relatively nonexpansive mapping from $C$ into itself, and let $\left\{\alpha_{n}\right\}$ be a sequence of real numbers such that $0 \leq \alpha_{n}<1$ and $\lim \sup _{n \rightarrow \infty}<1$. Suppose that $\left\{x_{n}\right\}$ is given by

$$
\left\{\begin{array}{l}
x_{0}=x \in C \text { chosen arbitrarily } \\
y_{n}=J^{-1}\left(\alpha_{n} J x_{n}+\left(1-\alpha_{n}\right) J T x_{n}\right) \\
H_{n}=\left\{z \in C: \phi\left(z, y_{n}\right) \leq \phi\left(z, x_{n}\right)\right\} \\
W_{n}=\left\{z \in C:\left\langle x_{n}-z, J x-J x_{n}\right\rangle \geq 0\right\} \\
x_{n+1}=P_{H_{n} \cap W_{n}} x_{0}, n=0,1,2, \ldots
\end{array}\right.
$$

where $J$ is the duality mapping on $E$. If $F(T)$ is nonempty, then $\left\{x_{n}\right\}$ converges strongly to $P_{F}(T)^{x}$, where $P_{F(T)}$ is the generalized projection from $C$ onto $F(T)$. In 2008, liduka and Takahashi [45] introduced the following iterative scheme for finding a solution of the variational inequality problem for an inverse-strongly monotone operator $A$ in a 2-uniformly convex and uniformly smooth Banach space $E: x_{1}=x \in C$ and

$$
x_{n+1}=\Pi_{C} J^{-1}\left(J x_{n}-\lambda_{n} A x_{n}\right),
$$

for every $n=1,2,3, \ldots$, where $\Pi_{C}$ is the generalized metric projection from $E$ onto $C$, $J$ is the duality mapping from $E$ into $E^{*}$ and $\left\{\lambda_{n}\right\}$ is a sequence of positive real numbers. They proved that the sequence $\left\{x_{n}\right\}$ generated by (1.12) converges weakly to some element of $\operatorname{VI}(A, C)$.

A popular method is the shrinking projection method which introduced by Takahashi et al. [46] in year 2008. Many authors developed the shrinking projection method for solving (mixed) equilibrium problems and fixed point problems in Hilbert and Banch spaces; see, [12,15,16,47-57] and references therein.

Recently, Qin et al. [58] further extended Theorem MT by considering a pair of asymptotically quasi- $\varphi$-nonexpansive mappings. To be more precise, they proved the following results.

Theorem QCK. Let $E$ be a uniformly smooth and uniformly convex Banach space and $C$ a nonempty closed and convex subset of E. Let $T: C \rightarrow C$ be a closed and asymptotically quasi- $\varphi$-nonexpansive mapping with the sequence $\left\{k_{n}^{(t)}\right\} \subset[1, \infty)$ such that $k_{n}^{(t)} \rightarrow 1$ as $n \rightarrow \infty$ and $S: C \rightarrow C$ a closed and asymptotically quasi- $\varphi$-nonexpansive mapping with the sequence $\left\{k_{n}^{(t)}\right\} \subset[1, \infty)$ such that $k_{n}^{(s)} \rightarrow 1$ as $n \rightarrow \infty$. Let $\left\{\alpha_{n}\right\}$, $\left\{\beta_{n}\right\},\left\{\gamma_{n}\right\}$ and $\left\{\delta_{n}\right\}$ be real number sequences in $[0,1]$.

Assume that $T$ and $S$ are uniformly asymptotically regular on $C$ and $\Omega=F(T) \cap F(S)$ is nonempty and bounded. Let $\left\{x_{n}\right\}$ be a sequence generated in the following manner: 


$$
\left\{\begin{array}{l}
x_{0} \in E \text { chosen arbitrarily, } \\
C_{1}=C \\
x_{1}=\Pi_{C_{1}} x_{0} \\
z_{n}=J^{-1}\left(\beta_{n} J x_{n}+\gamma_{n} J\left(T^{n} x_{n}\right)+\delta_{n} J\left(S^{n} x_{n}\right)\right) \\
y_{n}=J^{-1}\left(\alpha_{n} J x_{n}+\left(1-\alpha_{n}\right) J z_{n}\right) \\
C_{n+1}=\left\{w \in C_{n}: \phi\left(w, y_{n}\right) \leq \phi\left(w, x_{n}\right)+\left(k_{n}-1\right) M_{n}\right\} \\
x_{n+1}=\Pi_{C_{n+1}} x_{0}
\end{array}\right.
$$

where $k_{n}=\max \left\{k_{n}^{(t)}, k_{n}^{(s)}\right\}$ for each $n \geq 1, J$ is the duality mapping on $E$, and $M_{n}=\sup$ $\left\{\varphi\left(z, x_{n}\right): z \in \Omega\right\}$ for each $n \geq 1$. Assume that the control sequences $\left\{\alpha_{n}\right\},\left\{\beta_{n}\right\},\left\{\gamma_{n}\right\}$ and $\left\{\delta_{n}\right\}$ satisfy the following restrictions :

(a) $\beta_{n}+\gamma_{n}+\delta_{n}=1, \forall n \geq 1$;

(b) $\lim \inf _{n \rightarrow \infty} \gamma_{n} \delta_{n}, \lim _{n \rightarrow \infty} \beta_{n}=0$;

(c) $0 \leq \alpha_{n}<1$ and $\lim \sup _{n \rightarrow \infty} \alpha_{n}<1$.

On the other hand, Chang, Lee and Chan [59] proved a strong convergence theorem for finding a common element of the set of solutions for a generalized equilibrium problem (1.4) and the set of common fixed points for a pair of relatively nonexpansive mappings in Banach spaces. They proved the following results.

Theorem CLC. Let $E$ be a uniformly smooth and uniformly convex Banach space, $C$ be a nonempty closed convex subset of $E$. Let $A: C \rightarrow E^{*}$ be a $\alpha$-inverse-strongly monotone mapping and $f: C \times C \rightarrow \mathbb{R}$ be a bifunction satisfying the conditions (A1) (A4). Let $S, T: C \rightarrow C$ be two relatively nonexpansive mappings such that $\Omega:=F(T) \cap$ $F(S) \cap \operatorname{GEP}(f, A)$. Let $\left\{x_{n}\right\}$ be the sequence generated by

$$
\left\{\begin{array}{l}
x_{0} \in C \text { chosen arbitrarily, } \\
z_{n}=J^{-1}\left(\alpha_{n} J x_{n}+\left(1-\alpha_{n}\right) J T x_{n}\right), \\
y_{n}=J^{-1}\left(\beta_{n} J x_{n}+\left(1-\beta_{n}\right) J S x_{n}\right), \\
u_{n} \in C \text { such that } \\
\quad f\left(u_{n}, y\right)+\left\langle A u_{n}, y-u_{n}\right\rangle+\frac{1}{r_{n}}\left\langle y-u_{n}, J u_{n}-J y_{n}\right\rangle \geq 0, \forall y \in C, \\
H_{n}=\left\{v \in C: \phi\left(v, u_{n}\right) \leq \beta_{n} \phi\left(v, x_{n}\right)+\left(1-\beta_{n}\right) \phi\left(v, x_{n}\right)\right\} \\
W_{n}=\left\{z \in C:\left\langle x_{n}-z_{1} J x_{0}-J x_{n}\right\rangle \geq 0\right\} \\
x_{n+1}=\Pi_{H_{n} \cap W_{n}} x_{0}, \forall n \geq 0,
\end{array}\right.
$$

where $\left\{\alpha_{n}\right\}$ and $\left\{\beta_{n}\right\}$ are sequences in $[0,1]$ and $\left\{\gamma_{n}\right\} \subset[a, 1)$ for some $a>0$. If the following conditions are satisfied

(a) $\lim \inf _{n \rightarrow \infty} \alpha_{n}\left(1-\alpha_{n}\right)>0$;

(b) $\lim \inf _{n \rightarrow \infty} \beta_{n}\left(1-\beta_{n}\right)>0$;

then, $\left\{x_{n}\right\}$ converges strongly to $\Pi_{\Omega} x_{0}$, where $\Pi_{\Omega}$ is the generalized projection of $E$ onto $\Omega$.

Very recently, Kim [60], considered the shrinking projection methods which were introduced by Takahashi et al. [46] for asymptotically quasi- $\varphi$-nonexpansive mappings in a uniformly smooth and strictly convex Banach space which has the Kadec-Klee property. 
In this article, motivated and inspired by the study of Matsushita and Takahashi [44], Qin et al. [58], Kim [60], and Chang et al. [59], we introduce a new hybrid projection iterative scheme based on the shrinking projection method for finding a common element of the set of solutions of the generalized mixed equilibrium problems, the set of the variational inequality and the set of common fixed points for a pair of asymptotically quasi- $\varphi$-nonexpansive mappings in Banach spaces. The results obtained in this article improve and extend the recent ones announced by Matsushita and Takahashi [44], Qin et al. [58], Chang et al. [59] and many others.

\section{Preliminaries}

For the sake of convenience, we first recall some definitions and conclusions which will be needed in proving our main results.

In the sequel, we denote the strong convergence, weak convergence and weak* convergence of a sequence $\left\{x_{n}\right\}$ by $x_{n} \rightarrow x, x_{n} \rightarrow^{*} \times$ and $x_{n} \rightarrow^{*} x$, respectively.

It is well known that a uniformly convex Banach space has the Kadec-Klee property, i.e. if $x_{n} \rightarrow x$ and $\left\|x_{n}\right\| \rightarrow\|x\|$, then $x_{n} \rightarrow x$.

Lemma 2.1. ([31,61]) Let $E$ be a smooth, strictly convex and reflexive Banach space and $C$ be anonempty closed convex subset. Then, the following conclusion hold:

$$
\phi\left(x, \Pi_{C} \gamma\right)+\phi\left(\Pi_{C} \gamma, y\right) \leq \phi(x, y) ; \quad \forall x \in C, \quad y \in E .
$$

Lemma 2.2. ([34]). If E be a 2-uniformly convex Banach space and $0<c \leq 1$. Then, for all $x, y \in E$ we have

$$
\|x-y\| \leq \frac{2}{c^{2}}\|J x-J y\|,
$$

where $J$ is the normalized duality mapping of $E$.

The best constant $\frac{1}{c}$ in Lemma is called the p-uniformly convex constant of $E$.

Lemma 2.3. ([62]). If E be a p-uniformly convex Banach space and $p$ be a given real number with $p \geq 2$, then for all $x, y \in E, j_{x} \in J_{p} x$ and $j_{y} \in J_{p} y$

$$
\left\langle x-y, j_{x}-j_{y}\right\rangle \geq \frac{c^{p}}{2^{p-2} p}\|x-y\|^{p},
$$

where $J_{p}$ is the generalized duality mapping of $E$ and $\frac{1}{c}$ is the p-uniformly convexity constant of $E$.

Lemma 2.4. ([63]) Let $E$ be a uniformly convex Banach space and $B_{r}(0)$ a closed ball of $E$. Then, there exists a continuous strictly increasing convex function $g:[0, \infty) \rightarrow[0$, $\infty)$ with $g(0)=0$ such that

$$
\|\alpha x+(1-\alpha) y\|^{2} \leq \alpha\|x\|^{2}+(1-\alpha)\|y\|^{2}-\alpha(1-\alpha) g(\| x-y||)
$$

for all $x, y \in B_{r}(0)$ and $\alpha \in[0,1]$.

Lemma 2.5. ([58]) Let $E$ be a uniformly convex and smooth Banach space, $C$ a nonempty closed convex subset of $E$ and $T: C \rightarrow C$ a closed asymptotically quasi- $\varphi$-nonexpansive mapping. Then, $F(T)$ is a closed convex subset of $C$. 
Lemma 2.6. ([61]) Let $E$ be a smooth and uniformly convex Banach space. Let $x_{n}$ and $y_{n}$ be sequences in $E$ such that either $\left\{x_{n}\right\}$ or $\left\{y_{n}\right\}$ is bounded. If $\lim _{n \rightarrow \infty} \varphi\left(x_{n}, y_{n}\right)=0$, then $\lim _{n \rightarrow \infty}|| x_{n}-y_{n}||=0$.

Lemma 2.7. (Alber [31]). Let $C$ be a nonempty closed convex subset of a smooth Banach space $E$ and $x \in E$. Then, $x_{0}=\Pi_{C} x$ if and only if

$$
\left\langle x_{0}-y, J x-J x_{0}\right\rangle \geq 0, \quad \forall y \in C .
$$

Let $E$ be a reflexive, strictly convex, smooth Banach space and $J$ the duality mapping from $E$ into $E^{*}$. Then, $J^{1}$ is also single valued, one-to-one, surjective, and it is the duality mapping from $E^{*}$ into $E$. We make use of the following mapping $V$ studied in Alber [31]

$$
V\left(x, x^{*}\right)=\|x\|^{2}-2\left\langle x, x^{*}\right\rangle+\left\|x^{*}\right\|^{2},
$$

for all $x \in E$ and $x^{*} \in E^{*}$; that is, $V\left(x, x^{*}\right)=\varphi\left(x, J^{1} x^{*}\right)$.

Lemma 2.8. (Kohsaka and Takahashi [[64], Lemma 3.2]). Let E be a reflexive, strictly convex smooth Banach space and let $V$ be as in (2.1). Then,

$$
V\left(x, x^{*}\right)+2\left\langle J^{-1} x^{*}-x, y^{*}\right\rangle \leq V\left(x, x^{*}+y^{*}\right),
$$

for all $\times \in E$ and $x^{*}, y^{*} \in E^{*}$.

Proof. Let $x \in E$. Define $g\left(x^{*}\right)=V\left(x, x^{*}\right)$ and $f\left(x^{*}\right)=\left\|x^{*}\right\|^{2}$ for all $x^{*} \in E^{*}$. Since $J^{-1}$ is the duality mapping from $E^{*}$ to $E$, we have

$$
\partial g\left(x^{*}\right)=\partial(-2\langle x, \cdot\rangle+f)\left(x^{*}\right)=-2 x+2 J(-1)\left(x^{*}\right), \quad \forall x^{*} \in E^{*} .
$$

Hence, we get

$$
g\left(x^{*}\right)+2\left\langle J^{-1}\left(x^{*}\right)-x, y^{*}\right\rangle \leq g\left(x^{*}+y^{*}\right),
$$

that is,

$$
V\left(x, x^{*}\right)+2\left\langle J^{-1}\left(x^{*}\right)-x, y^{*}\right\rangle \leq V\left(x, x^{*}+y^{*}\right),
$$

for all $x^{*}, y^{*} \in E^{*}$.

For solving the generalized equilibrium problem, let us assume that the nonlinear mapping $A: C \rightarrow E^{*}$ is $\alpha$-inverse strongly monotone and the bifunction $f: C \times C \rightarrow \mathbb{R}$ satisfies the following conditions:

(A1) $f(x, x)=0 \forall x \in C$;

(A2) $f$ is monotone, i.e., $f(x, y)+f(y, x) \leq 0, \forall x, y \in C$;

(A3) $\lim \sup _{t \downarrow 0} f(x+t(z-x), y) \leq f(x, y), \forall x, y, z \in C$;

(A4) the function $y \mapsto f(x, y)$ is convex and lower semicontinuous.

Lemma 2.9. ([1]) Let E be a smooth, strictly convex and reflexive Banach space and $C$ be a nonempty closed convex subset of $E$. Let $f: C \times C \rightarrow \mathbb{R}$ be a bifunction satisfying the conditions $(A 1)-(A 4)$. Let $r>0$ and $x \in E$, then there exists $z \in C$ such that

$$
f(z, y)+\frac{1}{r}\langle y-z, J z-J x\rangle \geq 0, \quad \forall y \in C .
$$


Lemma 2.10. ([65]) Let $C$ be a closed convex subset of a uniformly smooth and strictly convex Banach space $E$ and let $f$ be a bifunction from $C \times C$ to $\mathbb{R}$ satisfying (A1) - (A4). For $r>0$ and $\times \in E$, define a mapping $T_{r}: E \rightarrow C$ as follows:

$$
T_{r}(x)=\left\{z \in C: f(z, y)+\frac{1}{r}\langle y-z, J z-J x\rangle \geq 0, \quad \forall y \in C\right\},
$$

for all $\times \in$ C. Then, the following conclusions holds:

(1) $T_{r}$ is single-valued;

(2) $T_{r}$ is a firmly nonexpansive-type mapping, i.e.

$$
\left\langle T_{r} x-T_{r} y_{,} J T_{r} x-J T_{r} y\right\rangle \leq\left\langle T_{r} x-T_{r} y_{,} J x-J y\right\rangle, \quad \forall x, y \in E ;
$$

(A3) $F\left(T_{r}\right)=\mathrm{EP}(f)$;

(A4) $\mathrm{EP}(f)$ is a closed convex.

Lemma 2.11. ([19]) Let $C$ be a closed convex subset of a smooth, strictly convex and reflexive Banach space $E$, let $f$ be a bifunction from $C \times C$ to $\mathbb{R}$ satisfying $(A 1)-(A 4)$ and let $r>0$. Then, for $x \in E$ and $q \in F\left(T_{r}\right)$,

$$
\phi\left(q, T_{r} x\right)+\phi\left(T_{r}(x), x\right) \leq \phi(q, x) .
$$

Lemma 2.12. ([66]) Let $C$ be a closed convex subset of a smooth, strictly convex and reflexive Banach space $E$. Let $B: C \rightarrow E^{*}$ be a continuous and monotone mapping, $\phi$ : $C \rightarrow \mathbb{R}$ be a lower semi-continuous and convex function, and $f$ be a bifunction from $C$ $\times C$ to $\mathbb{R}$ satisfying $(A 1)-(A 4)$. For $r>0$ and $\times \in E$, then there exists $u \in C$ such that

$$
f(u, y)+\langle B u, y-u\rangle+\varphi(y)-\varphi(u)+\frac{1}{r}\langle y-u, J u-J x\rangle, \quad \forall y \in C .
$$

Define a mapping $K_{r}: C \rightarrow C$ as follows:

$$
K_{r}(x)=\left\{u \in C: f(u, y)+\langle B u, y-u\rangle+\varphi(y)-\varphi(u)+\frac{1}{r}\langle y-u, J u-J x\rangle \geq 0, \quad \forall y \in C\right\}
$$

for all $x \in C$. Then, the following conclusions holds:

(a) $K_{r}$ is single-valued ;

(b) $K_{r}$ is a firmly nonexpansive-type mapping, i.e.;

$$
\left\langle K_{r} x-K_{r} y_{,} J K_{r} x-J K_{r} y\right\rangle \leq\left\langle K_{r} x-K_{r} y_{,} J x-J y\right\rangle, \quad \forall x, y \in E ;
$$

(c) $F\left(K_{r}\right)=\hat{F}\left(K_{r}\right)=\operatorname{GMEP}(f, B, \varphi)$;

(d) $\operatorname{GMEP}(f, B, \phi)$ is a closed convex,

(e) $\varphi\left(q, K_{r} z\right)+\varphi\left(K_{r} z, z\right) \leq \varphi(q, z), \forall q \in F\left(K_{r}\right), z \in E$.

Remark 2.13. ([66]) It follows from Lemma 2.12 that the mapping $K_{r}: C \rightarrow C$ defined by (2.3) is a relatively nonexpansive mapping. Thus, it is quasi- $\varphi$-nonexpansive. 
Let $C$ be a nonempty closed convex subset of a Banach space $E$ and let $A$ be an inverse-strongly monotone mapping of $C$ into $E^{*}$ which is said to be hemicontinuous if for all $x, y \in C$, the mapping $F$ of $[0,1]$ into $E^{*}$, defined by $F(t)=A(t x+(1-t) y)$, is continuous with respect to the weak* topology of $E^{*}$. We define by $N_{C}(v)$ the normal cone for $C$ at a point $v \in C$, that is,

$$
N_{C}(v)=\left\{x^{*} \in E^{*}:\left\langle v-y, x^{*}\right\rangle \geq 0, \quad \forall y \in C\right\} .
$$

Lemma 2.14. (Rockafellar [23]). Let $C$ be a nonempty, closed convex subset of a Banach space E, and A a monotone, hemicontinuous operator of $C$ into $E^{*}$. Let $U: E \rightrightarrows$ $E^{*}$ be an operator defined as follows:

$$
U v=\left\{\begin{array}{l}
A v+N_{C}(v), \quad v \in C \\
0, \text { otherwise }
\end{array}\right.
$$

Then, $U$ is maximal monotone and $U^{-1} 0=\operatorname{VI}(A, C)$.

\section{Main results}

In this section, we shall prove a strong convergence theorem for finding a common element of the set of solutions for a generalized mixed equilibrium problem (1.2), set of variational inequalities for an $\alpha$-inverse strongly monotone mapping and the set of common fixed points for a pair of asymptotically quasi- $\varphi$-nonexpansive mappings in Banach spaces.

Theorem 3.1. Let E be a uniformly smooth and 2-uniformly convex Banach space, $C$ be a nonempty closed convex subset of $E$. Let $A$ be an $\alpha$-inverse-strongly monotone mapping of $C$ into $E^{*}$ satisfying $\|A y\| \leq\|A y-A u\|, \forall y \in C$ and $u \in \operatorname{VI}(A, C) \neq \varnothing$. Let $B$ : $C \rightarrow E^{*}$ be a continuous and monotone mapping and $f: C \times C \rightarrow \mathbb{R}$ be a bifunction satisfying the conditions $(A 1)-(A 4)$, and $\phi: C \rightarrow \mathbb{R}$ be a lower semi-continuous and convex function. Let $T: C \rightarrow C$ be a closed and asymptoticallyquasi- $\varphi$-nonexpansive mapping with the sequence $\left\{k_{n}^{(t)}\right\} \subset[1, \infty)$ such that $k_{n}^{(t)} \rightarrow 1$ as $n \rightarrow \infty$ and $S: C \rightarrow C$ be a closed and asymptotically quasi- $\varphi$-nonexpansive mapping with the sequence $\left\{k_{n}^{(s)}\right\} \subset[1, \infty)$ such that $k_{n}^{(s)} \rightarrow 1$ as $n \rightarrow \infty$. Assume that $T$ and $S$ are uniformly asymptotically regular on $C$ and $\Omega:=F(T) \cap F(S) \cap \operatorname{VI}(A, C) \cap \operatorname{GMEP}(f, B, \phi.) \neq \varnothing$.

Let $\left\{x_{n}\right\}$ be the sequence defined by $x_{0} \in E$ and

$$
\left\{\begin{array}{l}
x_{1}=\Pi_{C_{1}} x_{0} \text { and } C_{1}=C_{,} \\
w_{n}=\Pi_{C} J^{-1}\left(J x_{n}-\lambda_{n} A x_{n}\right) \\
z_{n}=J^{-1}\left(\alpha_{n} J x_{n}+\left(1-\alpha_{n}\right) J T^{n} w_{n}\right) \\
y_{n}=J^{-1}\left(\beta_{n} J x_{n}+\left(1-\beta_{n}\right) J S^{n} z_{n}\right) \\
u_{n} \in C, \text { such that } \\
f\left(u_{n}, y\right)+\left\langle B u_{n}, y-u_{n}\right\rangle+\varphi(y)-\varphi\left(u_{n}\right)+\frac{1}{r_{n}}\left\langle y-u_{n}, J u_{n}-J y_{n}\right\rangle \geq 0, \forall y \in C, \\
C_{n+1}=\left\{z \in C_{n}: \phi\left(z, u_{n}\right) \leq \phi\left(z, x_{n}\right)+\theta_{n}\right\} \\
x_{n+1}=\Pi_{C_{n+1}} x_{0}, \quad \forall n \geq 1
\end{array}\right.
$$

where $\theta_{n}=\left(1-\beta_{n}\right)\left(k_{n}^{2}-1\right) M_{n} \rightarrow 0$ as $n \rightarrow \infty, k_{n}=\max \left\{k_{n}^{(t)}, k_{n}^{(s)}\right\}$ for each $n \geq 1, M_{n}$ $=\sup \left\{\varphi\left(z, x_{n}\right): z \in \Omega\right\}$ for each $n \geq 1,\left\{\alpha_{n}\right\}$ and $\left\{\beta_{n}\right\}$ are sequences in $[0,1],\left\{\lambda_{n}\right\} \subset[a$, $b$ ] for some $a, b$ with $0<a<b<c^{2} \alpha / 2$, where $\frac{1}{c}$ is the 2-uniformly convexity constant of $E$ and $\left\{r_{n}\right\} \subset[d, \infty)$ for some $d>0$. Suppose that the following conditions are 
satisfied: $\lim \inf _{n \rightarrow \infty}\left(1-\alpha_{n}\right)>0$ and $\lim \inf _{n \rightarrow \infty}\left(1-\beta_{n}\right)>0$. Then, the sequence $\left\{x_{n}\right\}$ converges strongly to $\Pi_{\Omega} x_{0}$, where $\Pi_{\Omega}$ is generalized projection of $E$ onto $\Omega$.

Proof. We have several steps to prove this theorem as follows:

Step 1. We first show that $C_{n+1}$ is closed and convex for each $n \geq 1$. Indeed, it is obvious that $C_{1}=C$ is closed and convex. Suppose that $C_{i}$ is closed and convex for each $i \in \mathbb{N}$. Next, we prove that $C_{i+1}$ is closed and convex. For any $z \in C_{i+1}$, we know that $\varphi\left(z, u_{i}\right) \leq \varphi\left(z, x_{i}\right)+\theta_{i}$ is equivalent to

$$
2\left\langle z, J x_{i}-J u_{i}\right\rangle \leq\left\|x_{i}\right\|^{2}-\left\|u_{i}\right\|^{2}+\theta_{i}
$$

where $\theta_{i}=\left(1-\beta_{i}\right)\left(k_{i}^{2}-1\right) M_{i}$ and $M_{i}=\sup \left\{\varphi\left(z, x_{i}\right): z \in \Omega\right\}$ for each $i \geq 1$. Hence, $C_{i+1}$ is closed and convex. Then, for each $n \geq 1$, we see that $C_{n}$ is closed and convex. Hence, $\Pi_{C_{n}}$ is well defined.

By the same argument as in the proof of [[43], Lemma 2.4], one can show that $F(T)$ $\cap F(S)$ is closed and convex. We also know that $\operatorname{VI}(A, C)=U^{-1} 0$ is closed and convex, and hence from Lemma 2.12(d), $\Omega:=F(S) \cap F(T) \cap \operatorname{VI}(A, C) \cap \operatorname{GMEP}(f, B, \phi)$ is a nonempty, closed and convex subset of $C$. Consequently, $\Pi_{\Omega}$ is well defined.

Step 2. We show that the sequence $\left\{x_{n}\right\}$ is well defined. Next, we prove that $\Omega \subset C_{n}$ for each $n \geq 1$. If $n=1, \Omega \subset C_{1}=C$ is obvious. Suppose that $\Omega \subset C_{i}$ for some positive integer $i$. For every $q \in \Omega$, we obtain from the assumption that $q \in C_{i}$. It follows, from Lemma 2.1 and Lemma 2.8, that

$$
\begin{aligned}
\phi\left(q, w_{i}\right) & =\phi\left(q, \Pi_{C} J^{-1}\left(J x_{i}-\lambda_{i} A x_{i}\right)\right) \\
& \leq \phi\left(q, J^{-1}\left(J x_{i}-\lambda_{i} A x_{i}\right)\right) \\
& =V\left(q, J x_{i}-\lambda_{i} A x_{i}\right) \\
& \leq V\left(q,\left(J x_{i}-\lambda_{i} A x_{i}\right)+\lambda_{i} A x_{i}\right)-2\left\langle J^{-1}\left(J x_{i}-\lambda_{i} A x_{i}\right)-q, \lambda_{i} A x_{i}\right\rangle \\
& =V\left(q, J x_{i}\right)-2 \lambda_{i}\left\langle J^{-1}\left(J x_{i}-\lambda_{i} A x_{i}\right)-q, A x_{i}\right\rangle \\
& =\phi\left(q, x_{i}\right)-2 \lambda_{i}\left\langle x_{i}-q, A x_{i}\right\rangle+2\left\langle J^{-1}\left(J x_{i}-\lambda_{i} A x_{i}\right)-x_{i},-\lambda_{i} A x_{i}\right\rangle .
\end{aligned}
$$

Thus, $q \in \operatorname{VI}(A, C)$ and $A$ is $\alpha$-inverse-strongly monotone, we have

$$
\begin{aligned}
-2 \lambda_{i}\left\langle x_{i}-q, A x_{i}\right\rangle & =-2 \lambda_{i}\left\langle x_{i}-q, A x_{i}-A q\right\rangle-2 \lambda_{i}\left\langle x_{i}-q, A q\right\rangle \\
& \leq-2 \lambda_{i}\left\langle x_{i}-q, A x_{i}-A q\right\rangle \\
& =-2 \alpha \lambda_{i}\left\|A x_{i}-A q\right\|^{2} .
\end{aligned}
$$

From Lemma 2.2 and $\|A y\| \leq\|A y-A u\|$ for all $y \in C$ and $q \in \Omega$, we obtain

$$
\begin{aligned}
2\left\langle J^{-1}\left(J x_{i}-\lambda_{i} A x_{i}\right)-x_{i},-\lambda_{i} A x_{i}\right\rangle & =2\left\langle J^{-1}\left(J x_{i}-\lambda_{i} A x_{i}\right)-J^{-1}\left(J x_{i}\right),-\lambda_{i} A x_{i}\right\rangle \\
& \leq 2\left\|J^{-1}\left(J x_{i}-\lambda_{i} A x_{i}\right)-J^{-1}\left(J x_{i}\right)\right\|\left\|\lambda_{i} A x_{i}\right\| \\
& \leq \frac{4}{c^{2}}\left\|J J^{-1}\left(J x_{i}-\lambda_{i} A x_{i}\right)-J J^{-1}\left(J x_{i}\right)\right\|\left\|\lambda_{i} A x_{i}\right\| \\
& =\frac{4}{c^{2}}\left\|J x_{i}-\lambda_{i} A x_{i}-J x_{i}\right\|\left\|\lambda_{i} A x_{i}\right\| \\
& =\frac{4}{c^{2}}\left\|\lambda_{i} A x_{i}\right\|^{2} \\
& =\frac{4}{c^{2}} \lambda_{i}^{2}\left\|A x_{i}\right\|^{2} \\
& \leq \frac{4}{c^{2}} \lambda_{i}^{2}\left\|A x_{i}-A q\right\|^{2} .
\end{aligned}
$$


Substituting (3.3) and (3.4) into (3.2), we have

$$
\begin{aligned}
\phi\left(q, w_{i}\right) & \leq \phi\left(q, x_{i}\right)-2 \alpha \lambda_{i}\left\|A x_{i}-A q\right\|^{2}+\frac{4}{c^{2}} \lambda_{i}^{2}\left\|A x_{i}-A q\right\|^{2} \\
& =\phi\left(q, x_{i}\right)+2 \lambda_{i}\left(\frac{2}{c^{2}} \lambda_{i}-\alpha\right)\left\|A x_{i}-A q\right\|^{2} \\
& \leq \phi\left(q, x_{i}\right) .
\end{aligned}
$$

As $T^{i}$ is asymptotically quasi- $\varphi$-nonexpansive mapping, we also have

$$
\begin{aligned}
\phi\left(q, z_{i}\right)= & \phi\left(q, J^{-1}\left(\alpha_{i} J x_{i}+\left(1-\alpha_{i}\right) J T^{i} w_{i}\right)\right) \\
= & \|q\|^{2}-2\left\langle q, \alpha_{i} J x_{i}+\left(1-\alpha_{i}\right) J T^{i} w_{i}\right\rangle+\left\|\alpha_{i} J x_{i}+\left(1-\alpha_{i}\right) J T^{i} w_{i}\right\|^{2} \\
\leq & \|q\|^{2}-2 \alpha_{i}\left\langle q, J x_{i}\right\rangle-2\left(1-\alpha_{i}\right)\left\langle q, J T^{i} w_{i}\right\rangle \\
& +\alpha_{i}\left\|x_{i}\right\|^{2}+\left(1-\alpha_{i}\right)\left\|T^{i} w_{i}\right\|^{2} \\
= & \alpha_{i} \phi\left(q, x_{i}\right)+\left(1-\alpha_{i}\right) \phi\left(q, T^{i} w_{i}\right) \\
\leq & \alpha_{i} \phi\left(q, x_{i}\right)+\left(1-\alpha_{i}\right) k_{i}^{(t)} \phi\left(q, w_{i}\right) \\
\leq & \alpha_{i} \phi\left(q, x_{i}\right)+\left(1-\alpha_{i}\right) k_{i} \phi\left(q, w_{i}\right) \\
\leq & \phi\left(q, x_{i}\right)+\left(k_{i}-1\right) \phi\left(q, w_{i}\right) .
\end{aligned}
$$

It follows that

$$
\begin{aligned}
\phi\left(q, u_{i}\right) & =\phi\left(q, K_{r_{i}} y_{i}\right) \leq \phi\left(q, y_{i}\right) \\
& \leq \phi\left(q, J^{-1}\left(\beta_{i} J x_{i}+\left(1-\beta_{i}\right) J S^{i} z_{i}\right)\right) \\
& =\|q\|^{2}-2\left\langle q, \beta_{i} J x_{i}+\left(1-\beta_{i}\right) J S^{i} z_{i}\right\rangle+\left\|\beta_{i} J x_{i}+\left(1-\beta_{i}\right) J S^{i} z_{i}\right\|^{2} \\
& \leq\|q\|^{2}-2 \beta_{i}\left\langle q, J x_{i}\right\rangle-2\left(1-\beta_{i}\right)\left\langle q, J S^{i} z_{i}\right\rangle+\beta_{i}\left\|x_{i}\right\|^{2}+\left(1-\beta_{i}\right)\left\|S^{i} z_{i}\right\|^{2} \\
& =\beta_{i} \phi\left(q, x_{i}\right)+\left(1-\beta_{i}\right) \phi\left(q, S^{i} z_{i}\right) \\
& \leq \beta_{i} \phi\left(q, x_{i}\right)+\left(1-\beta_{i}\right) k_{i}^{(s)} \phi\left(q, z_{i}\right) \\
& \leq \beta_{i} \phi\left(q, x_{i}\right)+\left(1-\beta_{i}\right) k_{i} \phi\left(q, z_{i}\right) \\
& =\left(1-\left(1-\beta_{n}\right)\right) \phi\left(q, x_{i}\right)+\left(1-\beta_{i}\right) k_{i} \phi\left(q, z_{i}\right) \\
& =\phi\left(q, x_{i}\right)+\left(1-\beta_{i}\right)\left[k_{i} \phi\left(q, z_{i}\right)-\phi\left(q, x_{i}\right)\right] \\
& \leq \phi\left(q, x_{i}\right)+\left(1-\beta_{i}\right)\left[k_{i}\left(\phi\left(q, x_{i}\right)+\left(k_{i}-1\right) \phi\left(q, w_{i}\right)\right)-\phi\left(q, x_{i}\right)\right] \\
& \leq \phi\left(q, x_{i}\right)+\left(1-\beta_{i}\right)\left[k_{i}\left(\phi\left(q, x_{i}\right)+\left(k_{i}-1\right) \phi\left(q, x_{i}\right)\right)-\phi\left(q, x_{i}\right)\right] \\
& \left.=\phi\left(q, x_{i}\right)+\left(1-\beta_{i}\right)\left[k_{i} \phi\left(q, x_{i}\right)+\left(k_{i}^{2}-k_{i}\right) \phi\left(q, x_{i}\right)-\phi\left(q, x_{i}\right)\right)\right] \\
& =\phi\left(q, x_{i}\right)+\left(1-\beta_{i}\right)\left(k_{i}^{2}-1\right) \phi\left(q, x_{i}\right) \\
& \leq \phi\left(q, x_{i}\right)+\left(1-\beta_{i}\right)\left(k_{i}^{2}-1\right) M_{i} \\
& =\phi\left(q, x_{i}\right)+\theta_{i} .
\end{aligned}
$$

This shows that $q \in C_{i+1}$. This implies that $\Omega \subset C_{n}$ for each $n \geq 1$.

From $x_{n}=\prod_{C_{n}} x_{0}$, we see that

$$
\left\langle x_{n}-q, J x_{0}-J x_{n}\right\rangle \geq 0, \quad \forall q \in C_{n} .
$$

Since $\Omega \subset C_{n}$ for each $n \geq 1$, we arrive at

$$
\left\langle x_{n}-q, J x_{0}-J x_{n}\right\rangle \geq 0, \quad \forall q \in \Omega .
$$

Hence, the sequence $\left\{x_{n}\right\}$ is well defined.

Step 3. Now, we prove that $\left\{x_{n}\right\}$ is bounded. 
In view of Lemma 2.1 , we see that

$$
\phi\left(x_{n}, x_{0}\right)=\phi\left(\prod_{C_{n}} x_{0}, x_{0}\right) \leq \phi\left(q, x_{0}\right)-\phi\left(q, x_{n}\right) \leq \phi\left(q, x_{0}\right),
$$

for each $q \in C_{n}$. Therefore, we obtain that the sequence $\varphi\left(x_{n}, x_{0}\right)$ is bounded, and so are $\left\{x_{n}\right\},\left\{w_{n}\right\},\left\{y_{n}\right\},\left\{z_{n}\right\},\left\{T^{n} w_{n}\right\}$ and $\left\{S^{n} x_{n}\right\}$.

Step 4. We show that $\left\{x_{n}\right\}$ is a Cauchy sequence.

Since $x_{n}=\prod_{C_{n}} x_{0}$ and $x_{n+1}=\prod_{C_{n+1}} x_{0} \in C_{n+1} \subset C_{n}$, we have

$$
\phi\left(x_{n}, x_{0}\right) \leq \phi\left(x_{n+1}, x_{0}\right), \quad \forall n \geq 1 .
$$

This implies that $\left\{\varphi\left(x_{n}, x_{0}\right)\right\}$ is nondecreasing, and $\lim _{n \rightarrow \infty} \varphi\left(x_{n}, x_{0}\right)$ exists.

For $m>n$ and from Lemma 2.1, we have

$$
\begin{aligned}
\phi\left(x_{m^{\prime}} x_{n}\right) & =\phi\left(x_{m^{\prime}} \Pi_{C_{n}} x_{0}\right) \leq \phi\left(x_{m^{\prime}} x_{0}\right)-\phi\left(\Pi_{C_{n}} x_{0}, x_{0}\right) \\
& =\phi\left(x_{m^{\prime}} x_{0}\right)-\phi\left(x_{n^{\prime}} x_{0}\right) .
\end{aligned}
$$

Letting $m, n \rightarrow \infty$ in (3.9), we see that $\varphi\left(x_{m}, x_{n}\right) \rightarrow 0$. It follows from Lemma 2.6 that $\left\|x_{m}-x_{n}\right\| \rightarrow 0$ as $m, n \rightarrow \infty$. Hence, $\left\{x_{n}\right\}$ is a Cauchy sequence. Since $E$ is a Banach space and $C$ is closed and convex, we can assume that $p \in C$ such that $x_{n} \rightarrow p$ as $n \rightarrow \infty$.

Step 5. We will show that $p \in \Omega:=F(T) \cap F(S) \cap \operatorname{VI}(A, C) \cap \operatorname{GMEP}(f, B, \phi)$.

(a) First, we show that $p \in F(T) \cap F(S)$.

By taking $m=n+1$ in (3.9), we obtain that

$$
\lim _{n-\infty} \phi\left(x_{n+1}, x_{n}\right)=0 .
$$

Since $x_{n+1}=\Pi_{C_{n+1}} x_{1} \in C_{n+1} \subset C_{n}$, from definition of $C_{n+1}$, we have

$$
\phi\left(x_{n+1}, u_{n}\right) \leq \phi\left(x_{n+1}, x_{n}\right)+\theta_{n}, \quad \forall n \geq 1,
$$

and from (3.5) and (3.6), we also have

$$
k_{n} \phi\left(x_{n+1}, z_{n}\right) \leq \phi\left(x_{n+1}, x_{n}\right)+\left(k_{n}^{2}-1\right) M_{n}, \quad \forall n \geq 1 .
$$

Since $E$ is uniformly smooth and uniformly convex, from (3.10)-(3.12), $\theta_{n} \rightarrow 0$ as $n$ $\rightarrow \infty$ and

Lemma 2.6, it follows that

$$
\lim _{n-\infty}\left\|x_{n+1}-x_{n}\right\|=\lim _{n-\infty}\left\|x_{n+1}-u_{n}\right\|=\lim _{n-\infty}\left\|x_{n+1}-z_{n}\right\|=0,
$$

and by using triangle inequality, we have

$$
\lim _{n-\infty}\left\|x_{n}-u_{n}\right\|=\lim _{n-\infty}|| x_{n}-z_{n}\left\|=\lim _{n-\infty}|| x_{n}-z_{n}\right\|=0 .
$$

Since $J$ is uniformly norm-to-norm continuous, we also have

$$
\lim _{n-\infty}\left\|J x_{n}-J u_{n}\right\|=0 .
$$

and

$$
\lim _{n-\infty}\left\|J x_{n}-J z_{n}\right\|=0 .
$$


Since $u_{n}=K_{r_{n}} y_{n}$, and from (3.7), we have

$$
\phi\left(u, y_{n}\right) \leq \phi\left(u, x_{n}\right)+\theta_{n}, \quad \forall u \in \Omega .
$$

Since $\left\|x_{n}-u_{n}\right\| \rightarrow 0$ and $J$ is uniformly continuous, we have

$$
\begin{aligned}
\phi\left(u_{n}, y_{n}\right) & =\phi\left(K_{r_{n}} y_{n}, y_{n}\right) \\
& \leq \phi\left(u, y_{n}\right)-\phi\left(u, K_{r_{n}} y_{n}\right) \\
& \leq \phi\left(u, x_{n}\right)-\phi\left(u, K_{r_{n}} y_{n}\right)+\theta_{n} \\
& =\phi\left(u, x_{n}\right)-\phi\left(u, u_{n}\right)+\theta_{n} \\
& =\left\|x_{n}\right\|^{2}-\left\|u_{n}\right\|^{2}-2\left\langle u, J x_{n}-J u_{n}\right\rangle+\theta_{n} \\
& \leq\left\|x_{n}-u_{n}\right\|\left(\left\|x_{n}\right\|+\left\|u_{n}\right\|\right)-2\left\langle u, J x_{n}-J u_{n}\right\rangle+\theta_{n} \rightarrow 0 .
\end{aligned}
$$

Since $\left\{x_{n}\right\}$ and $\left\{u_{n}\right\}$ are bounded, it follows from (3.14) and (3.15) that $\varphi\left(y_{n}, u_{n}\right) \rightarrow 0$ as $n \rightarrow \infty$. Since $E$ is smooth and uniformly convex, from Lemma 2.6, we have

$$
\left\|y_{n}-u_{n}\right\| \rightarrow 0 \text {, and so }\left\|y_{n}-x_{n}\right\| \rightarrow 0 \text { as } n \rightarrow \infty \text {. }
$$

Since $J$ is uniformly norm-to-norm continuous, we also have

$$
\left\|J y_{n}-J u_{n}\right\| \rightarrow 0 \text {, and }\left\|J y_{n}-J x_{n}\right\| \rightarrow 0 \text { as } n \rightarrow \infty .
$$

Again from (3.1) and (3.16), we have

$$
\left\|J z_{n}-J x_{n}\right\|=\left(1-\alpha_{n}\right)\left\|J T^{n} w_{n}-J x_{n}\right\| \rightarrow 0 \text { as } n \rightarrow \infty .
$$

This implies that $\left\|J T^{n} w_{n}-J x_{n}\right\| \rightarrow 0$. Again since $J^{-1}$ is uniformly norm-to-norm continuous, we also have

$$
\left\|T^{n} w_{n}-x_{n}\right\| \rightarrow 0 \text { as } n \rightarrow \infty .
$$

For $p \in \Omega$, we note that

$$
\left\|T^{n} w_{n}-p\right\| \leq\left\|T^{n} w_{n}-x_{n}\right\|+\left\|x_{n}-p\right\| .
$$

It follows from (3.22) and $x_{n} \rightarrow p$ as $n \rightarrow \infty$, that

$$
\lim _{n-\infty}\left\|T^{n} w_{n}-p\right\|=0
$$

On other hand, we have

$$
\left\|T^{n+1} w_{n}-p\right\| \leq\left\|T^{n+1} w_{n}-T^{n} w_{n}\right\|+\left\|T^{n} w_{n}-p\right\| .
$$

Since $T$ is uniformly asymptotically regular and from (3.24), we obtain that

$$
\left\|T^{n+1} w_{n}-p\right\|=0 .
$$

Thai is, $T T^{n w} n \rightarrow p$ as $n \rightarrow \infty$. From the closedness of $T$, we see that $p \in F(T)$. Furthermore, For $q \in \Omega$, from (3.7) and (3.18) that 


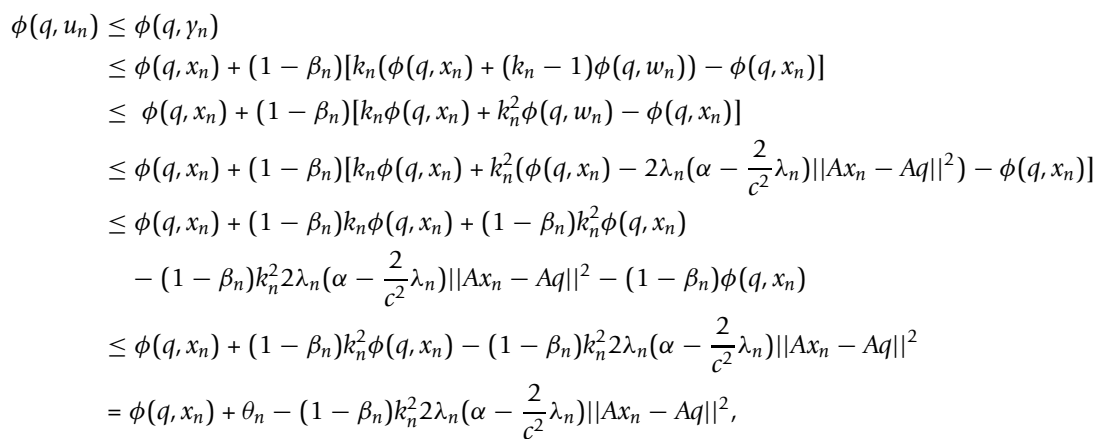

and hence

$$
\begin{aligned}
2 a\left(\alpha-\frac{2 b}{c^{2}}\right)\left\|A x_{n}-A q\right\|^{2} & \leq 2 \lambda_{n}\left(\alpha-\frac{2}{c^{2}} \lambda_{n}\right)\left\|A x_{n}-A q\right\|^{2} \\
& \leq \frac{1}{\left(1-\beta_{n}\right) k_{n}^{2}}\left(\phi\left(q, x_{n}\right)-\phi\left(q, u_{n}\right)+\theta_{n}\right) .
\end{aligned}
$$

From (3.18) and $\lim \inf _{n \rightarrow \infty}\left(1-\beta_{n}\right)>0$, obtain that

$$
\lim _{n \rightarrow \infty}\left\|A x_{n}-A q\right\|=0
$$

From Lemma 2.1, Lemma 2.8 and (3.4), we compute

$$
\begin{aligned}
\phi\left(x_{n}, w_{n}\right) & =\phi\left(x_{n}, \Pi_{C} J^{-1}\left(J x_{n}-\lambda_{n} A x_{n}\right)\right) \\
& \leq \phi\left(x_{n}, J^{-1}\left(J x_{n}-\lambda_{n} A x_{n}\right)\right) \\
& =V\left(x_{n}, J x_{n}-\lambda_{n} A x_{n}\right) \\
& \leq V\left(x_{n},\left(J x_{n}-\lambda_{n} A x_{n}\right)+\lambda_{n} A x_{n}\right)-2\left\langle J^{-1}\left(J x_{n}-\lambda_{n} A x_{n}\right)-x_{n}, \lambda_{n} A x_{n}\right\rangle \\
& =\phi\left(x_{n}, x_{n}\right)+2\left\langle J^{-1}\left(J x_{n}-\lambda_{n} A x_{n}\right)-x_{n},-\lambda_{n} A x_{n}\right\rangle \\
& =2\left\langle J^{-1}\left(J x_{n}-\lambda_{n} A x_{n}\right)-x_{n},-\lambda_{n} A x_{n}\right\rangle \\
& \leq \frac{4 \lambda_{n}^{2}}{c^{2}}\left\|A x_{n}-A q\right\|^{2} \\
& \leq \frac{4 b^{2}}{c^{2}}\left\|A x_{n}-A q\right\|^{2} .
\end{aligned}
$$

Applying Lemma 2.6 and (3.27) that

$$
\lim _{n \rightarrow \infty}\left\|x_{n}-w_{n}\right\|=0 .
$$

Since $J$ is uniformly norm-to-norm continuous on bounded sets, by (3.28), we have

$$
\lim _{n \rightarrow \infty}\left\|J x_{n}-J w_{n}\right\|=0 .
$$

From(3.1), (3.20) and (ii), we have

$$
\left\|J y_{n}-J x_{n}\right\|=\left(1-\beta_{n}\right)\left\|J S^{n} z_{n}-J x_{n}\right\| \rightarrow 0 \text { as } n \rightarrow \infty .
$$

Since $J^{1}$ is uniformly norm-to-norm continuous on bounded sets

$$
\left\|S^{n} z_{n}-x_{n}\right\| \rightarrow 0 \text { as } n \rightarrow \infty .
$$

We observe that

$$
\left\|S^{n} z_{n}-p\right\| \leq\left\|S^{n} z_{n}-x_{n}\right\|+\left\|x_{n}-p\right\| .
$$


It follows from (3.31) and $x_{n} \rightarrow p$ as $n \rightarrow \infty$, we obtain

$$
\lim _{n \rightarrow \infty}\left\|S^{n} z_{n}-p\right\|=0 .
$$

On other hand, we have

$$
\left\|S^{n+1} z_{n}-p\right\| \leq\left\|S^{n+1} z_{n}-S^{n} z_{n}\right\|+\left\|S^{n} z_{n}-p\right\| .
$$

Since $S$ is uniformly asymptotically regular and (3.33), we obtain that

$$
\left\|S^{n+1} z_{n}-p\right\|=0 .
$$

that is, $S S^{n} z_{n} \rightarrow p$ as $n \rightarrow \infty$. From the closedness of $S$, we see that $p \in F(S)$. Hence, $p \in F(T) \cap F(S)$.

(b) We show that $p \in \operatorname{GMEP}(f, B, \phi)$. From (A2), we have

$$
\left\langle B u_{n}, y-u_{n}\right\rangle+\varphi(y)-\varphi\left(u_{n}\right)+\frac{1}{r_{n}}\left\langle y-u_{n}, J u_{n}-J y_{n}\right\rangle \geq f\left(y, u_{n}\right), \quad \forall y \in C,
$$

and hence

$$
\left\langle B u_{n}, y-u_{n}\right\rangle+\varphi(y)-\varphi\left(u_{n}\right)+\left\langle y-u_{n}, \frac{\left(J u_{n}-J y_{n}\right)}{r_{n}}\right\rangle \geq f\left(y, u_{n}\right), \quad \forall y \in C .
$$

For $t$ with $0<t \leq 1$ and $y \in C$, let $y_{t}=t_{y}+(1-t) p$. Then, we get $y_{t} \in C$. From (3.35), it follows that

$$
\begin{aligned}
\left\langle B y_{t}, y_{t}-u_{n}\right\rangle & \geq\left\langle B y_{t}, y_{t}-u_{n}\right\rangle-\left\langle B u_{n}, y_{t}-u_{n}\right\rangle-\varphi\left(y_{t}\right)+\varphi\left(u_{n}\right)-\left\langle y_{t}-u_{n}, \frac{\left(J u_{n}-J y_{n}\right)}{r_{n}}\right\rangle+f\left(y_{t}, u_{n}\right) \\
& \geq\left\langle B y_{t}-B u_{n}, y_{t}-u_{n}\right\rangle-\varphi\left(y_{t}\right)+\varphi\left(u_{n}\right)-\left\langle y_{t}-u_{n} \frac{\left(J u_{n}-J y_{n}\right)}{r_{n}}\right\rangle+f\left(y_{t}, u_{n}\right), \quad \forall y_{t} \in C .
\end{aligned}
$$

we know that $y_{n}, u_{n} \rightarrow p$ as $n \rightarrow \infty$, and $\frac{\left\|u_{n}-J y_{n}\right\|}{r_{n}} \rightarrow 0$ as $n \rightarrow \infty$. Since $B$ is monotone, we know that $\left\langle B y_{t}-B u_{n}, y_{t}-u_{n}\right\rangle \geq 0$. Thus, it follows from (A4) that

$$
\begin{aligned}
f\left(y_{t}, p\right)-\varphi\left(y_{t}\right)+\varphi(p) & \leq \liminf _{n \rightarrow \infty} f\left(y_{t}, u_{n}\right)-\varphi\left(y_{t}\right)+\varphi\left(u_{n}\right) \leq \lim _{n \rightarrow \infty}\left\langle B y_{t}, y_{t}-u_{n}\right\rangle \\
& =\left\langle B y_{t}, y_{t}-p\right\rangle .
\end{aligned}
$$

Based on the conditions (A1), (A4) and convexity of $\phi$, we have

$$
\begin{aligned}
0 & =f\left(y_{t}, y_{t}\right)+\varphi\left(y_{t}\right)-\varphi\left(y_{t}\right) \\
& \leq t f\left(y_{t}, y\right)+(1-t) f\left(y_{t}, p\right)+t \varphi(y)+(1-t) \varphi(p)-\varphi\left(y_{t}\right) \\
& =t\left[f\left(y_{t}, y\right)+\varphi(\gamma)-\varphi\left(y_{t}\right)\right]+(1-t)\left[f\left(y_{t}, p\right)+\varphi(p)-\varphi\left(y_{t}\right)\right] \\
& \leq t\left[f\left(y_{t}, y\right)+\varphi(\gamma)-\varphi\left(y_{t}\right)\right]+(1-t)\left[\left\langle B y_{t}, y_{t}-p\right\rangle\right] \\
& =t\left[f\left(y_{t}, y\right)+\varphi(\gamma)-\varphi\left(y_{t}\right)\right]+(1-t) t\left[\left\langle B y_{t}, y-p\right\rangle\right]
\end{aligned}
$$

and hence

$$
0 \leq f\left(y_{t}, \gamma\right)+\varphi(\gamma)-\varphi\left(y_{t}\right)+(1-t)\left\langle B y_{t}, y-p\right\rangle .
$$

From (A3) and the weakly lower semicontinuity of $\phi$, and letting $t \rightarrow 0$, we also have

$$
f(p, y)+\langle B p, y-p\rangle+\varphi(y)-\varphi(p) \geq 0, \quad \forall y \in C .
$$

This implies that $p \in \operatorname{GMEP}(f, B, \phi)$. 
(c) We show that $p \in \operatorname{VI}(A, C)$. Indeed, define a set-valued $U: E \rightrightarrows E^{*}$ by Lemma 2.14, $U$ is maximal monotone and $U^{-1} 0=\operatorname{VI}(A, C)$. Let $(v, w) \in G(U)$. Since $w \in$ $U v=A v+N_{C}(v)$, we get $w-A v \in N_{C}(v)$.

From $w_{n} \in C$, we have

$$
\left\langle v-w_{n}, w-A v\right\rangle \geq 0 .
$$

On the other hand, since $w_{n}=\Pi_{C} J^{-1}\left(J x_{n}-\lambda_{n} A x_{n}\right)$. Then from Lemma 2.7, we have

$$
\left\langle v-w_{n}, J w_{n}-\left(J x_{n}-\lambda_{n} A x_{n}\right)\right\rangle \geq 0,
$$

and thus

$$
\left\langle v-w_{n}, \frac{J x_{n}-J w_{n}}{\lambda_{n}}-A x_{n}\right\rangle \leq 0 .
$$

It follows from (3.36) and (3.37) that

$$
\begin{aligned}
\left\langle v-w_{n}, w\right\rangle & \geq\left\langle v-w_{n}, A v\right\rangle \\
& \geq\left\langle v-w_{n}, A v\right\rangle+\left\langle v-w_{n}, \frac{J x_{n}-J w_{n}}{\lambda_{n}}-A x_{n}\right\rangle \\
& =\left\langle v-w_{n}, A v-A x_{n}\right\rangle+\left\langle v-w_{n}, \frac{J x_{n}-J w_{n}}{\lambda_{n}}\right\rangle \\
& =\left\langle v-w_{n}, A v-A w_{n}\right\rangle+\left\langle v-w_{n}, A w_{n}-A x_{n}\right\rangle+\left\langle v-w_{n}, \frac{J x_{n}-J w_{n}}{\lambda_{n}}\right\rangle \\
& \geq-\left\|v-w_{n}\right\| \frac{\left\|w_{n}-x_{n}\right\|}{\alpha}-\left\|v-w_{n}\right\| \frac{\left\|J x_{n}-J w_{n}\right\|}{a} \\
& \geq-M\left(\frac{\left\|w_{n}-x_{n}\right\|}{\alpha}+\frac{\left\|J x_{n}-J w_{n}\right\|}{a}\right),
\end{aligned}
$$

where $M=\sup _{n \geq 1}\left\|v-w_{n}\right\|$. Takeing the limit as $n \rightarrow \infty$, (3.28) and (3.29), we obtain $\langle v-p, w\rangle \geq 0$. Based on the maximality of $U$, we have $p \in U^{-1} 0$ and hence $p \in$ $\mathrm{VI}(A, C)$. Hence, by (a), (b) and (c), we obtain $p \in \Omega$.

Step 5. Finally, we prove that $p=\Pi_{\Omega} x_{0}$. Taking the limit as $n \rightarrow \infty$ in (3.8), we obtain that

$$
\left\langle p-q, J x_{0}-J p\right\rangle \geq 0, \quad \forall q \in \Omega
$$

and hence, $p=\Pi_{\Omega} x_{0}$ by Lemma 2.1. This completes the proof.

The following Theorems can readily be derived from Theorem 3.1.

Corollary 3.2. Let $E$ be a uniformly smooth and 2-uniformly convex Banach space, and $C$ be a nonempty closed convex subset of $E$. Let $A$ be an $\alpha$-inverse-strongly monotone mapping of $C$ into $E^{*}$ satisfying $\|A y\| \leq\|A y-A u\|, \forall y \in C$ and $u \in \operatorname{VI}(A, C) \neq$ $\varnothing$,. Let $f: C \times C \rightarrow \mathbb{R}$ be a bifunction satisfying the conditions (A1) - (A4), and $\phi: C$ $\rightarrow \mathbb{R}$ be a lower semi-continuous and convex function. Let $T: C \rightarrow C$ be a closed and asymptotically quasi- $\varphi$-nonexpansive mapping with the sequence $\left\{k_{n}^{(t)}\right\} \subset[1, \infty)$ such that $k_{n}^{(t)} \rightarrow 1$ as $n \rightarrow \infty$ and $S: C \rightarrow C$ be a closed and asymptotically quasi- $\varphi$-nonexpansive mapping with the sequence $\left\{k_{n}^{(s)}\right\} \subset[1, \infty)$ such that $k_{n}^{(s)} \rightarrow 1$ as $n \rightarrow \infty$. Assume that $T$ and $S$ are uniformly asymptotically regular on $C$ and $\Omega:=F(T) \cap F(S) \cap \operatorname{VI}(A$, C) $\cap \operatorname{MEP}(f, \phi) \neq \varnothing$. Let $\left\{x_{n}\right\}$ be the sequence defined by $x_{0} \in E$ and 


$$
\left\{\begin{array}{l}
x_{1}=\Pi_{C_{1}} x_{0} \text { and } C_{1}=C, \\
w_{n}=\Pi_{C} J^{-1}\left(J x_{n}-\lambda_{n} A x_{n}\right), \\
z_{n}=J^{-1}\left(\alpha_{n} J x_{n}+\left(1-\alpha_{n}\right) J T^{n} w_{n}\right), \\
y_{n}=J^{-1}\left(\beta_{n} J x_{n}+\left(1-\beta_{n}\right) J S^{n} z_{n}\right), \\
u_{n} \in C_{1} \text { such that } \\
f\left(u_{n}, y\right)+\varphi(y)-\varphi\left(u_{n}\right)+\frac{1}{r_{n}}\left\langle y-u_{n}, J u_{n}-J y_{n}\right\rangle \geq 0, \quad \forall y \in C, \\
C_{n+1}=\left\{z \in C_{n}: \phi\left(z, u_{n}\right) \leq \beta_{n} \phi\left(z, x_{n}\right)+\left(1-\beta_{n}\right) k_{n} \phi\left(z, z_{n}\right) \leq \phi\left(z, x_{n}\right)+\theta_{n}\right\} \\
x_{n+1}=\Pi_{C_{n+1}} x_{0}, \quad \forall n \geq 1,
\end{array}\right.
$$

where $\theta_{n}=\left(1-\beta_{n}\right)\left(k_{n}^{2}-1\right) M_{n} \rightarrow 0$ as $n \rightarrow \infty, k_{n}=\max \left\{k_{n}^{(t)}, k_{n}^{(s)}\right\}$ for each $n \geq 1, M_{n}$ $=\sup \left\{\varphi\left(z, x_{n}\right): z \in \Omega\right\}$ for each $n \geq 1,\left\{\alpha_{n}\right\}$ and $\left\{\beta_{n}\right\}$ are sequences in $[0,1],\left\{\lambda_{n}\right\} \subset[a$, $b$ ] for some $a, b$ with $0<a<b<c^{2} \alpha / 2$, where $\frac{1}{c}$ is the 2-uniformly convexity constant of $E$ and $\left\{r_{n}\right\} \subset[d, \infty)$ for some $d>0$. Suppose that the following conditions are satisfied:

(i) $\lim \inf _{n \rightarrow \infty}\left(1-\alpha_{n}\right)>0$,

(ii) $\lim \inf _{n \rightarrow \infty}\left(1-\beta_{n}\right)>0$.

Then, the sequence $\left\{x_{n}\right\}$ converges strongly to $\Pi_{\Omega} x_{0}$, where $\Pi_{\Omega}$ is generalized projection of $E$ onto $\Omega$.

Proof. Putting $B \equiv 0$ in Theorem 3.1, the conclusion of Theorem 3.2 can be obtained.

Corollary 3.3. Let E be a uniformly smooth and 2-uniformly convex Banach space, $C$ be a nonempty closed convex subset of $E$. Let $A$ be an $\alpha$-inverse-strongly monotone mapping of $C$ into $E^{*}$ satisfying $\|A y\| \leq\|A y-A u\|, \forall y \in C$ and $u \in \operatorname{VI}(A, C) \neq \varnothing$. Let $B$ : $C \rightarrow E^{*}$ be a continuous and monotone mapping and $\phi: C \rightarrow \mathbb{R}$ be a lower semi-continuous and convex function. Let $T: C \rightarrow C$ be a closed and asymptotically quasi- $\varphi$ nonexpansive mapping with the sequence $\left\{k_{n}^{(t)}\right\} \subset[1, \infty)^{\text {such }}$ that $k_{n}^{(t)} \rightarrow 1$ as $n \rightarrow \infty$ and $S: C \rightarrow C$ be a closed and asymptotically quasi- $\varphi$-nonexpansive mapping with the sequence $\left\{k_{n}^{(s)}\right\} \subset[1, \infty)$ such that $k_{n}^{(s)} \rightarrow 1$ as $n \rightarrow \infty$. Assume that $T$ and $S$ are uniformly asymptotically regular on $C$ and $\Omega:=F(T) \cap F(S) \cap \operatorname{VI}(A, C) \cap \operatorname{MVI}(B, C) \neq \varnothing$. Let $\left\{x_{n}\right\}$ be the sequence defined by $x_{0} \in E$ and

$$
\left\{\begin{array}{l}
x_{1}=\Pi_{C_{1}} x_{0} \text { and } C_{1}=C, \\
w_{n}=\Pi_{C} J^{-1}\left(J x_{n}-\lambda_{n} A x_{n}\right), \\
z_{n}=J^{-1}\left(\alpha_{n} J x_{n}+\left(1-\alpha_{n}\right) J T^{n} w_{n}\right), \\
y_{n}=J^{-1}\left(\beta_{n} J x_{n}+\left(1-\beta_{n}\right) J S^{n} z_{n}\right), \\
u_{n} \in C, \text { such that } \\
\left\langle B u_{n}, y-u_{n}\right\rangle+\varphi(y)-\varphi\left(u_{n}\right)+\frac{1}{r_{n}}\left\langle y-u_{n}, J u_{n}-J y_{n}\right\rangle \geq 0, \quad \forall y \in C, \\
C_{n+1}=\left\{z \in C_{n}: \phi\left(z, u_{n}\right) \leq \beta_{n} \phi\left(z, x_{n}\right)+\left(1-\beta_{n}\right) k_{n} \phi\left(z, z_{n}\right) \leq \phi\left(z, x_{n}\right)+\theta_{n}\right\}, \\
x_{n+1}=\Pi_{C_{n+1}} x_{0}, \quad \forall n \geq 1,
\end{array}\right.
$$

where $\theta_{n}=\left(1-\beta_{n}\right)\left(k_{n}^{2}-1\right) M_{n} \rightarrow 0$ as $n \rightarrow \infty, k_{n}=\max \left\{k_{n}^{(t)}, k_{n}^{(s)}\right\}$ for each $n \geq 1, M_{n}$ $=\sup \left\{\varphi\left(z, x_{n}\right): z \in \Omega\right\}$ for each $n \geq 1,\left\{\alpha_{n}\right\}$ and $\left\{\beta_{n}\right\}$ are sequences in $[0,1],\left\{\lambda_{n}\right\} \subset[a$, b] for some $a, b$ with $0<a<b<c^{2} \alpha / 2$, where $\frac{1}{c}$ is the 2-uniformly convexity constant of $E$ and $\left\{r_{n}\right\} \subset[d, \infty)$ for some $d>0$. Suppose that the following conditions are 
satisfied:

(i) $\lim \inf _{n \rightarrow \infty}\left(1-\alpha_{n}\right)>0$;

(ii) $\lim \inf _{n \rightarrow \infty}\left(1-\beta_{n}\right)>0$.

Then, the sequence $\left\{x_{n}\right\}$ converges strongly to $\Pi_{\Omega} x_{0}$, where $\Pi_{\Omega}$ is generalized projection of $E$ onto $\Omega$.

Proof. Putting $f \equiv 0$ in Theorem 3.1, the conclusion of Theorem 3.2 can be obtained.

Since every closed relatively asymptotically nonexpansive mapping is asymptotically quasi- $\varphi$-nonexpansive, we obtain the following corollary.

Corollary 3.4. Let $E$ be a uniformly smooth and 2-uniformly convex Banach space, $C$ be a nonempty closed convex subset of $E$. Let $A$ be an $\alpha$-inverse-strongly monotone mapping of $C$ into $E^{*}$ satisfying $\|A y\| \leq\|A y-A u\|, \forall y \in C$ and $u \in \operatorname{VI}(A, C) \neq \varnothing$. Let $B$ : $C \rightarrow E^{*}$ be a continuous and monotone mapping and $f: C \times C \rightarrow \mathbb{R}$ be a bifunction satisfying the conditions (A1) - (A4), and $\phi . C \rightarrow \mathbb{R}$ be a lower semi-continuous and convex function. Let $T$. $C \rightarrow C$ be a closed and relatively asymptotically nonexpansive mapping with the sequence $\left\{k_{n}^{(t)}\right\} \subset[1, \infty)^{\text {such }}$ that $k_{n}^{(t)} \rightarrow 1$ as $n \rightarrow \infty$ and $S . C \rightarrow C$ be a closed and relatively asymptotically nonexpansive mapping with the sequence $\left\{k_{n}^{(s)}\right\} \subset[1, \infty)$ such that $k_{n}^{(s)} \rightarrow 1$ as $n \rightarrow \infty$. Assume that $T$ and $S$ are uniformly asymptotically regular on $C$ and $\Omega:=F(T) \cap F(S) \cap \operatorname{VI}(A, C) \cap \operatorname{GMEP}(f, B, \phi) \neq \varnothing$. Let $\left\{x_{n}\right\}$ be the sequence defined by $x_{0} \in E$ and

$$
\left\{\begin{array}{l}
x_{1}=\Pi_{C_{1}} x_{0} \text { and } C_{1}=C \\
w_{n}=\Pi_{C} J^{-1}\left(J x_{n}-\lambda_{n} A x_{n}\right) \\
z_{n}=J^{-1}\left(\alpha_{n} J x_{n}+\left(1-\alpha_{n}\right) J T^{n} w_{n}\right) \\
y_{n}=J^{-1}\left(\beta_{n} J x_{n}+\left(1-\beta_{n}\right) J S^{n} z_{n}\right) \\
u_{n} \in C, \text { such that } \\
f\left(u_{n}, y\right)+\left\langle B u_{n}, y-u_{n}\right\rangle+\varphi(y)-\varphi\left(u_{n}\right)+\frac{1}{r_{n}}\left\langle y-u_{n}, J u_{n}-J y_{n}\right\rangle \geq 0, \quad \forall y \in C, \\
C_{n+1}=\left\{z \in C_{n}: \phi\left(z, u_{n}\right) \leq \beta_{n} \phi\left(z, x_{n}\right)+\left(1-\beta_{n}\right) k_{n} \phi\left(z, z_{n}\right) \leq \phi\left(z, x_{n}\right)+\theta_{n}\right\} \\
x_{n+1}=\Pi_{C_{n+1}} x_{0}, \quad \forall n \geq 1
\end{array}\right.
$$

where $\theta_{n}=\left(1-\beta_{n}\right)\left(k_{n}^{2}-1\right) M_{n} \rightarrow$ 0as $n \rightarrow \infty, k_{n}=\max \left\{k_{n}^{(t)}, k_{n}^{(s)}\right\}$ for each $n \geq 1, M_{n}$ $=\sup \left\{\varphi\left(z, x_{n}\right) . z \in \Omega\right\}$ for each $n \geq 1,\left\{\alpha_{n}\right\}$ and $\left\{\beta_{n}\right\}$ are sequences in $[0,1],\left\{\lambda_{n}\right\} \subset[a$, b] for some $a, b$ with $0<a<b<c^{2} \alpha / 2$, where $\frac{1}{c}$ is the 2-uniformly convexity constant of $E$ and $\left\{r_{n}\right\} \subset[d, \infty)$ for some $d>0$. Suppose that the following conditions are satisfied:

(i) $\lim \inf _{n \rightarrow \infty}\left(1-\alpha_{n}\right)>0$;

(ii) $\lim \inf _{n \rightarrow \infty}\left(1-\beta_{n}\right)>0$.

Then, the sequence $\left\{x_{n}\right\}$ converges strongly to $\Pi_{\Omega} x_{0}$, where $\Pi_{\Omega}$ is generalized projection of $E$ onto $\Omega$.

Since every closed relatively nonexpansive mapping is asymptotically quasi- $\varphi$-nonexpansive, we obtain the following corollary.

Corollary 3.5. Let E be a uniformly smooth and 2-uniformly convex Banach space, $C$ be a nonempty closed convex subset of $E$. Let $A$ be an $\alpha$-inverse-strongly monotone 
mapping of $C$ into $E^{*}$ satisfying $\|A y\| \leq\|A y A u\|, \forall y \in C$ and $u \in \operatorname{VI}(A, C) \neq \varnothing$. Let $B: C \rightarrow E^{*}$ be a continuous and monotone mapping and $f: C \times C \rightarrow \mathbb{R}$ be a bifunction satisfying the conditions $(A 1)-(A 4)$, and $\phi: C \rightarrow \mathbb{R}$ be a lower semi-continuous and convex function. Let $T, S: C \rightarrow C$ be closed relatively nonexpansive mappings such that $\Omega:=F(T) \cap F(S) \cap \operatorname{VI}(A, C) \cap \operatorname{GMEP}(f, B, \phi) \neq \varnothing$. Let $\left\{x_{n}\right\}$ be the sequence defined by $x_{0} \in E$ and

$$
\left\{\begin{array}{l}
x_{1}=\Pi_{C_{1}} x_{0} \text { and } C_{1}=C, \\
w_{n}=\Pi_{C} J^{-1}\left(J x_{n}-\lambda_{n} A x_{n}\right), \\
z_{n}=J^{-1}\left(\alpha_{n} J x_{n}+\left(1-\alpha_{n}\right) J T w_{n}\right), \\
y_{n}=J^{-1}\left(\beta_{n} J x_{n}+\left(1-\beta_{n}\right) J S z_{n}\right), \\
u_{n} \in C, \text { such that } \\
f\left(u_{n}, y\right)+\left\langle B u_{n}, y-u_{n}\right\rangle+\varphi(y)-\varphi\left(u_{n}\right)+\frac{1}{r_{n}}\left\langle y-u_{n} J u_{n}-J y_{n}\right\rangle \geq 0, \quad \forall y \in C, \\
C_{n+1}=\left\{z \in C_{n}: \phi\left(z, u_{n}\right) \leq \beta_{n} \phi\left(z, x_{n}\right)+\left(1-\beta_{n}\right) k_{n} \phi\left(z, z_{n}\right) \leq \phi\left(z, x_{n}\right)\right\}, \\
x_{n+1}=\Pi_{C_{n+1}} x_{0}, \quad \forall n \geq 1,
\end{array}\right.
$$

where $\left\{\alpha_{n}\right\}$ and $\left\{\beta_{n}\right\}$ are sequences in $[0,1],\left\{\lambda_{n}\right\} \subset[a, b]$ for some $a, b$ with $0<a<b$ $<c^{2} \alpha / 2$, where $\frac{1}{c}$ is the 2-uniformly convexity constant of $E$ and $\left\{r_{n}\right\} \subset[d, \infty)$ for some $d$ $>0$. Suppose that the following conditions are satisfied:

(i) $\lim \inf _{n \rightarrow \infty}\left(1-\alpha_{n}\right)>0$,

(ii) $\lim \inf _{n \rightarrow \infty}\left(1-\beta_{n}\right)>0$.

Then, the sequence $\left\{x_{n}\right\}$ converges strongly to $\Pi_{\Omega} x_{0}$, where $\Pi_{\Omega}$ is generalized projection of $E$ onto $\Omega$.

Corollary 3.6. Let $E$ be a uniformly smooth and 2-uniformly convex Banach space, $C$ be a nonempty closed convex subset of $E$. Let $A$ be an $\alpha$-inverse-strongly monotone mapping of $C$ into $E^{*}$ satisfying $\|A y\| \leq\|A y-A u\|, \forall y \in C$ and $u \in \operatorname{VI}(A, C) \neq \varnothing$. Let $B$ : $C \rightarrow E^{*}$ be a continuous and monotone mapping and $f: C \times C \rightarrow \mathbb{R}$ be a bifunction satisfying the conditions $(A 1)-(A 4)$, and $\phi: C \rightarrow \mathbb{R}$ be a lower semi-continuous and convex function. Let $T, S: C \rightarrow C$ be a closed quasi- $\varphi$-nonexpansive mappings $\Omega:=F$ $(T) \cap F(S) \cap \operatorname{VI}(A, C) \cap \operatorname{GMEP}(f, B, \phi) \neq \varnothing$. Let $\left\{x_{n}\right\}$ be the sequence defined by $x_{0} \in E$ and

$$
\left\{\begin{array}{l}
x_{1}=\Pi_{C_{1}} x_{0} \text { and } C_{1}=C \\
w_{n}=\Pi_{C} J^{-1}\left(J x_{n}-\lambda_{n} A x_{n}\right) \\
z_{n}=J^{-1}\left(\alpha_{n} J x_{n}+\left(1-\alpha_{n}\right) J T w_{n}\right) \\
y_{n}=J^{-1}\left(\beta_{n} J x_{n}+\left(1-\beta_{n}\right) J S z_{n}\right) \\
u_{n} \in C, \text { such that } \\
f\left(u_{n}, y\right)+\left\langle B u_{n}, y-u_{n}\right\rangle+\varphi(y)-\varphi\left(u_{n}\right)+\frac{1}{r_{n}}\left\langle y-u_{n}, J u_{n}-J y_{n}\right\rangle \geq 0, \quad \forall y \in C \\
C_{n+1}=\left\{z \in C_{n}: \phi\left(z, u_{n}\right) \leq \beta_{n} \phi\left(z, x_{n}\right)+\left(1-\beta_{n}\right) k_{n} \phi\left(z, z_{n}\right) \leq \phi\left(z, x_{n}\right)+\theta_{n}\right\} \\
x_{n+1}=\Pi_{C_{n+1}} x_{0}, \quad \forall n \geq 1
\end{array}\right.
$$

where $\left\{\alpha_{n}\right\}$ and $\left\{\beta_{n}\right\}$ are sequences in $[0,1],\left\{\lambda_{n}\right\} \subset[a, b]$ for some $a, b$ with $0<a<$ $b<c^{2} \alpha / 2$, where $\frac{1}{c}$ is the 2 -uniformly convexity constant of $E$ and $\left\{r_{n}\right\} \subset[d, \infty)$ for some $d>0$. Suppose that the following conditions are satisfied: 
(i) $\lim \inf _{n \rightarrow \infty}\left(1-\alpha_{n}\right)>0$;

(ii) $\lim \inf _{n \rightarrow \infty}\left(1-\beta_{n}\right)>0$.

Then, the sequence $\left\{x_{n}\right\}$ converges strongly to $\Pi_{\Omega} x_{0}$, where $\Pi_{\Omega}$ is generalized projection of $E$ onto $\Omega$

Proof. Since every closed quasi- $\varphi$-nonexpansive mapping is asymptotically quasi- $\varphi$ nonexpansive, the result is implied by Theorem 3.1.

Corollary 3.7. Let $E$ be a uniformly smooth and 2-uniformly convex Banach space, $C$ be a nonempty closed convex subset of $E$. Let $A$ be an $\alpha$-inverse-strongly monotone mapping of $C$ into $E^{*}$ satisfying $\|A y\| \leq\|A y-A u\|, \forall y \in C$ and $u \in \operatorname{VI}(A, C) \neq \varnothing$. Let $B$ : $C \rightarrow E^{*}$ be a continuous and monotone mapping and $f: C \times C \rightarrow \mathbb{R}$ be a bifunction satisfying the conditions $(A 1)-(A 4)$, and $\phi: C \rightarrow \mathbb{R}$ be a lower semi-continuous and convex function. Let $T, S: C \rightarrow C$ be closed relatively nonexpansive mappings such that $\Omega:=F(T) \cap F(S) \cap \operatorname{VI}(A, C) \cap \operatorname{GMEP}(f, B, \phi) \neq \varnothing$. Let $\left\{x_{n}\right\}$ be the sequence defined by $x_{0} \in E$ and

$$
\left\{\begin{array}{l}
x_{1}=\Pi_{C_{1}} x_{0} \text { and } C_{1}=C \\
w_{n}=\Pi_{C} J^{-1}\left(J x_{n}-\lambda_{n} A x_{n}\right) \\
z_{n}=J^{-1}\left(\alpha_{n} J x_{n}+\left(1-\alpha_{n}\right) J T w_{n}\right) \\
y_{n}=J^{-1}\left(\beta_{n} J x_{n}+\left(1-\beta_{n}\right) J S z_{n}\right) \\
u_{n} \in C, \text { such that } \\
f\left(u_{n}, y\right)+\left\langle B u_{n}, y-u_{n}\right\rangle+\varphi(y)-\varphi\left(u_{n}\right)+\frac{1}{r_{n}}\left\langle y-u_{n} J u_{n}-J y_{n}\right\rangle \geq 0, \quad \forall y \in C \\
C_{n+1}=\left\{z \in C_{n}: \phi\left(z, u_{n}\right) \leq \beta_{n} \phi\left(z, x_{n}\right)+\left(1-\beta_{n}\right) k_{n} \phi\left(z, z_{n}\right) \leq \phi\left(z, x_{n}\right)+\theta_{n}\right\} \\
x_{n+1}=\Pi_{C_{n+1}} x_{0}, \quad \forall n \geq 1
\end{array}\right.
$$

where $\left\{\alpha_{n}\right\}$ and $\left\{\beta_{n}\right\}$ are sequences in $[0,1],\left\{\lambda_{n}\right\} \subset[a, b]$ for some $a, b$ with $0<a<b$ $<c^{2} \alpha / 2$, where $\frac{1}{c}$ is the 2-uniformly convexity constant of $E$ and $\left\{r_{n}\right\} \subset[d, \infty)$ for some $d$ $>0$. Suppose that the following conditions are satisfied:

(i) $\lim \inf _{n \rightarrow \infty}\left(1-\alpha_{n}\right)>0$;

(ii) $\lim \inf _{n \rightarrow \infty}\left(1-\beta_{n}\right)>0$.

Then, the sequence $\left\{x_{n}\right\}$ converges strongly to $\Pi_{\Omega} x_{0}$, where $\Pi_{\Omega}$ is generalized projection of $E$ onto $\Omega$.

Proof. Since every closed relatively nonexpansive mapping is quasi- $\varphi$-nonexpansive, the result is implied by Theorem 3.1.

Remark 3.8. Corollaries 3.7, 3.6 and 3.7 improve and extend the corresponding results of Saewan et al. [[51], Theorem 3.1] in the sense of changing the closed relatively quasi-nonexpansive mappings to be the more general than the closed and asymptotically quasi- $\varphi$-nonexpansive mappings and adjusting a problem from the classical equilibrium problem to be the generalized equilibrium problem.

\section{Acknowledgements}

The authors would like to thank Prof. Jong Kyu Kim and the anonymous referees for their respective helpful discussions and suggestions in preparation of this article. This research was supported by grant under the program Strategic Scholarships for Frontier Research Network for the Joint Ph.D. Program of Thai Doctoral degree from the Office of the Higher Education Commission, Thailand. Moreover, the first author was also supported by the King Mongkuts Daimond scholarship for Ph.D. program at King Mongkuts University of Technology Thonburi (KMUTT), 
under project NRU-CSEC no.54000267, and the second author was supported by the Higher Education Commission and the Thailand Research Fund under Grant MRG5380044. Furthermore, this work was partially supported by the Higher Education Research Promotion and National Research University Project of Thailand, Office of the Higher Education Commission.

\section{Authors' contributions}

SS designed and performed all the steps of proof in this research and also wrote the paper. PK participated in the design of the study and suggest many good ideas that made this paper possible and helped to draft the first manuscript. All authors read and approved the final manuscript.

\section{Competing interests}

The authors declare that they have no competing interests.

\section{Received: 23 November 2010 Accepted: 23 June 2011 Published: 23 June 2011}

\section{References}

1. Blum $E_{1}$ Oettli W: From optimization and variational inequalities to equilibrium problems. Math Stud 1994, 63:123-145.

2. Flores-Bazan F: Existence theory for finite-dimensional pseudomonotone equilibrium problems. Acta Appl Math 2003, 77:249-297.

3. Hadjisavvas N, Komlósi S, Schaible S: Handbook of Generalized Convexity and Generalized Monotonicity. Springer, Berlin; 2005.

4. Hadjisavvas N, Schaible S: From scalar to vector equilibrium problems in the quasimonotone case. J Optim Theory Appl 1998, 96:297-309.

5. Cai G, Hu CS: A hybrid approximation method for equilibrium and fixed point problems for a family of infinitely nonexpansive mappings and a monotone mapping. Nonlinear Anal.: Hybrid Syst 2009, 3:395-407.

6. Ceng LC, Yao JC: A hybrid iterative scheme for mixed equilibrium problems and fixed point problems. $J$ Comput Appl Math 2008, 214:186-201.

7. Combettes PL, Hirstoaga SA: Equilibrium programming in Hilbert spaces. J Nonlinear Convex Anal 2005, 6:117-136.

8. Flam SD, Antipin AS: Equilibrium programming using proximal-like algorithms. Math Program 1997, 78:29-41.

9. Jitpeera T, Kumam P: An extragradient type method for a system of equilibrium problems, variational inequality problems and fixed points of finitely many nonexpansive mappings. J Nonlinear Anal Optim.: Theory Appl 2010, 1(1):71-91.

10. Jaiboon C, Kumam $P$, Humphries UW: An extra gradient method for relaxed cocoercive variational inequality and equilibrium problems. Anal Theory Appl 2009, 25(4):381-400.

11. Kumam P: A Hybrid approximation method for equilibrium and fixed point problems for a monotone mapping and a nonexpansive mapping. Nonlinear Anal.: Hybrid Syst 2008, 2(4):1245-1255.

12. Kumam P: A new hybrid iterative method for solution of equilibrium problems and fixed point problems for an inverse strongly monotone operator and a nonexpansive mapping. J Appl Math Comput 2009, 29:263-280.

13. Kumam $P$, Petrot $N$, Wangkeeree R: A hybrid iterative scheme for equilibrium problems and fixed point problems of asymptotically k-strictly pseudo-contractions. J Comput Appl Math 2010, 233:2013-2026.

14. Petrot N, Wattanawitoon K, Kumam P: A hybrid projection method for generalized mixed equilibrium problems and fixed point problems in Banach spaces. Nonlinear Anal.: Hybrid Syst 2010, 4:631-643.

15. Saewan S, Kumam P: Modified hybrid block iterative algorithm for convex feasibility problems and generalized equilibrium problems for uniformly quasi-囚-asymptotically nonexpansive mappings. Abstr Appl Anal 2010, 22, Article ID 357120.

16. Saewan S, Kumam P: A hybrid iterative scheme for a maximal monotone operator and two countable families of relatively quasi-nonexpansive mappings for generalized mixed equilibrium and variational inequality problems. Abstr Appl Anal 2010, 31, Article ID 123027.

17. Tada A, Takahashi W: Strong convergence theorem for an equilibrium problem and a nonexpansive mapping. In Nonlinear Analysis and Convex Analysis. Edited by: Takahashi W, Tanaka T. Yokohama Publishers, Yokohama; 2006:609-617.

18. Takahashi S, Takahashi W: Viscosity approximation methods for equilibrium problems and fixed point problems in Hilbert spaces. J Math Anal Appl 2007, 331:506-515.

19. Takahashi W, Zembayashi K: Strong convergence theorem by a new hybrid method for equilibrium problems and relatively nonexpansive mappings. Fixed Point Theory Appl 2008, 11, Article ID 528476.

20. Wattanawitoon K, Kumam P, Humphries UW: Strong convergence theorem by the shrinking projection method for hemi-relatively nonexpansive mappings. Thai J Math 2009, 7(2):329-337.

21. Ball K, Carlen EA, Lieb EH: Sharp uniform convexity and smoothness inequalities for trace norm. Invent Math 1994 26:137-150.

22. Takahashi Y, Hashimoto K, Kato M: On sharp uniform convexity, smoothness, and strong type, cotype inequalities. $J$ Nonlinear Convex Anal 2002, 3:267-281.

23. Rockafellar RT: On the maximality of sums of nonlinear monotone operators. Trans Am Math Soc 1970, 149:75-88.

24. Cho SY, Kang SM, Qin X: Weak and strong convergence of an implicit iteration process for two families of asymptotically nonexpansive mappings. Thai J Math 2010, 8(3):521-533.

25. Katchang $P$, Kumam P: A new iterative algorithm of solution for equilibrium problems, variational inequalities and fixed point problems in a Hilbert space. J Appl Math Comput 2010, 32:19-38.

26. Nakajo K, Shimoji K, Takahashi W: Strong convergence theorems of Halpern's type for families of nonexpansive mappings in Hilbert spaces. 2009, 7(1):49-67.

27. Su Y, Shang M, Qin X: A general iterative scheme for nonexpansive mappings and inverse-strongly monotone mappings. J Appl Math Comput 2008, 28:283-294. 
28. Zhou H, Gao X: An iterative method of fixed points for closed and quasi-strict pseudo-contractions in Banach spaces. J Appl Math Comput 33(1-2):227-237.

29. Kirk WA: Metric fixed point theory: Old problems and new directions. Fixed Point Theory 2010, 11(1):45-58.

30. Goebel K, Kirk WA: A fixed point theorem for asymptotically nonexpansive mappings. Proc Am Math Soc 1972, 35:171-174.

31. Alber Y: Metric and generalized projection operators in Banach spaces: properties and applications. In Theory and Applications of Nonlinear Operator of Accretive and Monotone Type. Edited by: Kartsatos AG. Marcel Dekker, New York; 1996:15-50.

32. Agarwal RP, Cho YJ, Qin X: Generalized projection algorithms for nonlinear operators. Numer Funct Anal Optim 2007, 28:1197-1215.

33. Alber $Y$, Reich S: An iterative method for solving a class of nonlinear operator equations in Banach spaces. Panamer Math J 1994, 4:39-54.

34. Xu HK: Inequalities in Banach spaces with applications. Nonlinear Anal 1991, 16:1127-1138.

35. Cioranescu I: Geometry of Banach Spaces, Duality Mappings and Nonlinear Problems. Kluwer, Dordrecht; 1990

36. Takahashi W: Convex Analysis and Approximation Fixed points. Yokohama Publishers, Yokohama; 2000, (Japanese).

37. Reich S: A weak convergence theorem for the alternating method with Bregman distance. In Theory and Applications of Nonlinear Operators of Accretive and Monotone Type. Edited by: Kartsatos AG. Marcel Dekker, New York; 1996:313-318.

38. Butnariu D, Reich S, Zaslavski AJ: Asymptotic behavior of relatively nonexpansive operators in Banach spaces. J Appl Anal 2001, 7:151-174

39. Butnariu D, Reich S, Zaslavski AJ: Weak convergence of orbits of nonlinear operators in reflexive Banach spaces. Numer Funct Anal Optim 2003, 24:489-508.

40. Censor Y, Reich S: Iterations of para contractions and firmly nonexpansive operators with applications to feasibility and optimization. Optimization 1996, 37:323-339.

41. Qin X, Su Y, Wu C, Liu K: Strong convergence theorems for nonlinear operators in Banach spaces. Commun Appl Nonlinear Anal 2007, 14:35-50.

42. Qin X, Cho YJ, Kang SM: Convergence theorems of common elements for equilibrium problems and fixed point problems in Banach spaces. J Comput Appl Math 2009, 225:20-30.

43. Zhou H, Gao G, Tan B: Convergence theorems of a modified hybrid algorithm for a family of quasi-囚-asymptotically nonexpansive mappings. J Appl Math Comput 2010, 32(2):453-464.

44. Matsushita S, Takahashi W: Weak and strong convergence theorems for relatively nonexpansive mappings in Banach spaces. Fixed Point Theory Appl 2004, 1:37-47.

45. liduka $\mathrm{H}$, Takahashi W: Weak convergence of a projection algorithm for variational inequalities in a Banach space. $J$ Math Anal Appl 2008, 339:668-679.

46. Takahashi W, Takeuchi Y, Kubota R: Strong convergence theorems by hybrid methods for families of nonexpansive mapping in Hilbert spaces. J Math Anal Appl 2008, 341:276-286.

47. Jaiboon C, Kumam P: Strong convergence theorems for solving equilibrium problems and fixed point problems of E-strict pseudo-contraction mappings by two hybrid projection methods. J Comput Appl Math 2010, 234:722-732.

48. Wattanawitoon K, Kumam P: Strong convergence theorem by a new hybrid algorithm for fixed point problems and equilibrium problems of two relatively quasi-nonexpansive mappings. Nonlinear Anal.: Hybrid Syst 2009, 3(1):11-20, Corrigendum: Nonlinear Anal.: Hybrid Syst. 3(2), 176 (2009).

49. Kamraksa $U$, Wangkeeree R: A new hybrid method for solving generalized equilibrium problem and common fixed point in Banach spaces. J Nonlinear Anal Optim.: Theory Appl 2010, 1(1):55-69.

50. Kumam P, Wattanawitoon K: Convergence theorems of a hybrid algorithm for equilibrium problems. Nonlinear Anal.: Hybrid Syst 2009, 3:386-394.

51. Saewan S, Kumam P, Wattanawitoon K: Convergence theorem based on a new hybrid projection method for finding a common solution of generalized equilibrium and variational inequality problems in Banach spaces. Abstr Appl Anal 2010, 26, Article ID 734126.

52. Plubtieng $\mathrm{S}$, Thammathiwat $\mathrm{T}$ : Shrinking projection methods for a family of relatively nonexpansive mappings, equilibrium problems and variational inequality problems in Banach spaces. J Nonlinear Anal Optim.: Theory Appl 2010, 1(1):97-110.

53. Markshoe $\mathrm{P}$, Wangkeeree $\mathrm{R}$, Kamraksa U: The shrinking projection method for generalized mixed equilibrium problems and fixed point problems in Banach spaces. J Nonlinear Anal Optim.: Theory Appl 2010, 1(1):111-129.

54. Cholamjiak P, Suantai S: Convergence analysis for a system of equilibrium problems and a countable family of relatively quasi-nonexpansive mappings in Banach spaces. Abstr Appl Anal 2010, 17, Article ID 141376.

55. Liu M, Chang S-S, Zuo P: Shrinking projection method of common solutions for generalized equilibrium quasi- - nonexpansive mapping and relatively nonexpansive mapping. I Inequal App/ 15, Article ID 101690.

56. Wangkeeree $R$, Wangkeeree $R$ : The shrinking projection method for solving variational inequality problems and fixed point problems in banach spaces. Abstr Appl Anal 2009, 26, Article ID 624798.

57. Kang J, Su Y, Zhang X: Shrinking projection algorithm for fixed points of firmly nonexpansive mappings and its applications. Fixed Point Theory 2010, 11(2):301-310.

58. Qin X, Cho SY, Kang SM: On hybrid projection methods for asymptotically quasi-囚-nonexpansive mappings. Appl Math Comput 2010, 215:3874-3883.

59. Chang S-S, Joseph Lee HW, Chan CK: A new hybrid method for solving generalized equilibrium problem variational inequality and common fixed point in Banach spaces with applications. Nonlinear Anal 2010, 73:2260-2270.

60. Kim JK: Strong convergence theorem by hybrid projection methods for equilibriums problems and fixed point problems of the asymptotically quasi-囚-nonexpansive mappings. Fixed Point Theory Appl 2011, 1-20, Article ID 901256.

61. Kamimura S, Takahashi W: Strong convergence of a proximal-type algorithm in a Banach space. SIAM J Optim 2002, 13:938-945.

62. Beauzamy B: Introduction to Banach Spaces and their Geometry. Noth Holland, Amsterdam , 21985. 
63. Cho YJ, Zhou H, Guo G: Weak and strong convergence theorems for three-step iterations with errors for asymptotically nonexpansive mappings. Comput Math Appl 2004, 47:707-717.

64. Kohsaka F, Takahashi W: Strong convergence of an iterative sequence for maximal monotone operators in a Banach space. Abstr Appl Anal 2004, 3: 239-249.

65. Takahashi W, Zembayashi K: Strong and weak convergence theorems for equilibrium problems and relatively nonexpansive mappings in Banach spaces. Nonlinear Anal 2009, 70:45-57.

66. Zhang S: Generalized mixed equilibrium problem in Banach spaces. Appl Math Mech English Edition 2009, 30:1105-1112.

doi:10.1186/1687-1812-2011-9

Cite this article as: Saewan and Kumam: The shrinking projection method for solving generalized equilibrium problems and common fixed points for asymptotically quasi- $\varphi$-nonexpansive mappings. Fixed Point Theory and Applications 2011 2011:9.

\section{Submit your manuscript to a SpringerOpen ${ }^{\odot}$} journal and benefit from:

- Convenient online submission

Rigorous peer review

- Immediate publication on acceptance

- Open access: articles freely available online

- High visibility within the field

Retaining the copyright to your article

Submit your next manuscript at $\gg$ springeropen.com 